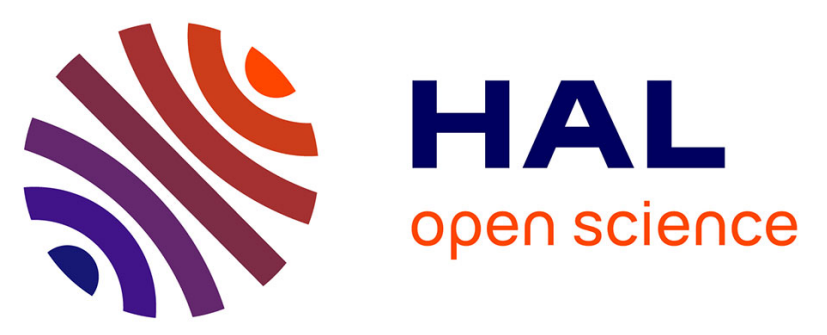

\title{
Global-scale evaluation of two satellite-based passive microwave soil moisture datasets (SMOS and AMSR-E) with respect to Land Data Assimilation System estimates
}

\author{
Amen Al-Yaari, Jean-Pierre Wigneron, Agnès Ducharne, Yann H. Kerr, \\ Patricia de Rosnay, Richard de Jeu, Ajit Govind, Al Bitar Ahmad, Clément \\ Albergel, Joaquin Munoz-Sabater, et al.
}

\section{- To cite this version:}

Amen Al-Yaari, Jean-Pierre Wigneron, Agnès Ducharne, Yann H. Kerr, Patricia de Rosnay, et al.. Global-scale evaluation of two satellite-based passive microwave soil moisture datasets (SMOS and AMSR-E) with respect to Land Data Assimilation System estimates. Remote Sensing of Environment, 2014, 140, pp.181-195. 10.1016/j.rse.2014.04.006 . hal-01062447

\author{
HAL Id: hal-01062447 \\ https://hal.science/hal-01062447
}

Submitted on 12 Sep 2014

HAL is a multi-disciplinary open access archive for the deposit and dissemination of scientific research documents, whether they are published or not. The documents may come from teaching and research institutions in France or abroad, or from public or private research centers.
L'archive ouverte pluridisciplinaire HAL, est destinée au dépôt et à la diffusion de documents scientifiques de niveau recherche, publiés ou non, émanant des établissements d'enseignement et de recherche français ou étrangers, des laboratoires publics ou privés. 
1 Global- scale evaluation of two satellite-based passive microwave soil moisture

2 datasets (SMOS and AMSR-E) with respect to Land Data Assimilation

4

4

5

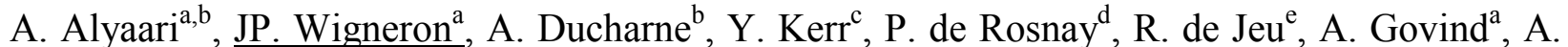
Al Bitar ${ }^{\mathrm{c}}$, C. Albergel ${ }^{\mathrm{d}}, \mathrm{J}_{\text {Muñoz-Sabater }}^{\mathrm{d}}$, P. Richaume $^{\mathrm{c}}$, A. Mialon $^{\mathrm{c}}$

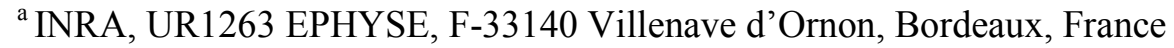

${ }^{\mathrm{b}}$ Sisyphe, Université Pierre-et-Marie Curie/CNRS, Paris, France

${ }^{c}$ Centre d'Etudes Spatiales de la BIOsphère (CESBIO - CNES, CNRS, IRD, Université Toulouse III), Toulouse, France

${ }^{\mathrm{d}}$ European Centre for Medium-Range Weather Forecasts (ECMWF), Reading, UK

${ }^{\mathrm{e}}$ Department of Earth Sciences, VU University Amsterdam, the Netherlands. 
Global Level-3 surface Soil Moisture (SM) maps derived from the passive microwave SMOS (Soil Moisture and Ocean Salinity) observations at L-band have recently been released. In this study, a comparative analysis of this Level 3 product (referred to as SMOSL3) along with another Surface SM (SSM) product derived from the observations of the Advanced Microwave Scanning Radiometer (AMSR-E) at C-band is presented (this latter product is referred to as AMSRM). SM-DAS-2, a SSM product produced by the European Centre for Medium Range Weather Forecasts (ECMWF) Land Data Assimilation System (LDAS) was used to monitor both SMOSL3 and AMSRM quality. The present study was carried out from 03/2010 to 09/2011, a period during which both SMOS and AMSR-E products were available at global scale. Three statistical metrics were used for the evaluation; the correlation coefficient $(\mathrm{R})$, the Root Mean Squared Difference (RMSD), and the bias. Results were analysed using maps of biomes and Leaf Area Index (LAI). It is shown that both SMOSL3 and AMSRM captured well the spatio-temporal variability of SM-DAS-2 for most of the biomes. In term of correlation values, the SMOSL3 product was found to better capture the SSM temporal dynamics in highly vegetated biomes ("tropical humid", "temperate humid", etc.) while best results for AMSRM were obtained over arid and semi-arid biomes (“desert temperate", "desert tropical", etc.). Finally, we showed that the accuracy of the remotely sensed SSM products is strongly related to LAI. Both the SMOSL3 and AMSRM (marginally better) SSM products correlated well with the SM-DAS-2 product over regions with sparse vegetation for values of LAI $\leq 1$ (these regions represent almost $50 \%$ of the pixels considered in this global study). In regions where LAI $>1$, SMOSL3 showed better correlations with SM-DAS-2 than AMSRM: SMOSL3 had a consistent performance up to $\mathrm{LAI}=6$, whereas the AMSRM performance deteriorated with increasing values of LAI. This study reveals that SMOS and AMSR-E complement one another 
in monitoring SSM over a wide range in conditions of vegetation density and that there are valuable satellite observed SSM data records over more than 10 years, which can be used to study land-atmosphere processes.

\section{Introduction}

Soil moisture (SM) is a key environmental variable, which interacts with vegetation and ecosystem functioning (Bolten et al., 2010; Daly \& Porporato, 2005), water resources (Dobriyal et al., 2012), and the climate system. It is central to land-atmosphere interactions due to its positive control on evapotranspiration, with feedback loops that are usually negative on air temperature (Cheruy et al., 2013), and still not well understood on rainfall (Taylor et al., 2012). SM also influences the dynamics of all the above mentioned processes by buffering or memory effects, with consequences on the persistence of extreme events, climate and hydrologic predictability, and even anthropogenic climate change trajectories (Entekhabi et al., 1996; Koster et al., 2010; Koster et al., 2004b; Quesada et al., 2012; Seneviratne et al., 2013; Thirel et al., 2010).

As a result, accurate SM initialization is crucial to the quality of most water-related environmental forecasts up to at least seasonal forecasts, including numerical weather predictions (NWP) (Beljaars et al., 1996; De Lannoy et al., 2013; de Rosnay et al., 2012; de Rosnay et al., 2013; Drusch \& Viterbo, 2007; Koster et al., 2006). In particular, it is important to achieve an accurate SM initialization at the scale of the forecast models, which can exceed $0.5^{\circ} \times 0.5^{\circ}$ for NWP and climate models. In situ SM measurements can now be routinely achieved with an accuracy as high as $0.025 \mathrm{~m}^{3} / \mathrm{m}^{3}$ (Walker et al., 2004). However, considering the high spatial variability of SM and the poor density of in situ measurement sites, it is not possible to produce 
accurate large-scale estimate of SM from in situ measurement networks (Dorigo et al., 2011; Hollinger \& Isard, 1994; Vivoni et al., 2008).

A major alternative to estimate SM at the large scale is to rely on remote sensing satellites, using passive or active microwave sensors, which offer global coverage and good temporal repetitivity, but are only sensitive to a shallow layer of the soil. Historically, passive microwave sensors were first used, starting with the Scanning Multichannel Microwave Radiometer (SMMR; 6.6, 10.7, 18.0 21, and $37 \mathrm{GHz}$ channels; Wang, 1985) which operated on Nimbus-7 between 1978 and 1987, then the Special Sensor Microwave Imager (SSM/I) which started in 1987. Later passive sensors include the microwave imager from the Tropical Rainfall Measuring Mission (TRMM; 10, 19 and $21 \mathrm{GHz}$ channel; Bindlish et al., 2003; Gao et al., 2006), the Advanced Microwave Scanning Radiometer on Earth Observing System (AMSR-E; from 6.9 to $89.0 \mathrm{GHz}$; Njoku \& Li, 1999) which operated on the AQUA satellite between 2002 and 2011, and Coriolis Windsat which started in 2003 (Parinussa et al., 2011a). More recently, the Soil Moisture and Ocean Salinity (SMOS; $1.4 \mathrm{GHz}$ ) was launched in 2009 (Kerr et al., 2010) and the upcoming SMAP (Soil Moisture Active/Passive) mission, including a radiometer at L-band, was planned by the National Aeronautics and Space Administration (NASA) and scheduled for launch in 2014 (Entekhabi et al., 2010). Low resolution active microwave sensors (scatterometers) have also been used (Bartalis et al., 2007; Wagner et al., 2007).

Among all these microwave sensors, SMOS is the first satellite dedicated and specifically designed to measure directly surface SM (SSM) and sea surface salinity on a global scale (Kerr et al., 2012; Kerr et al., 2010) owing to its polar-orbiting 2-D interferometric radiometer at Lband. The Level 2 SMOS SSM products (SMOSL2) are derived from the multiangular and fully polarized L-band passive microwave measurements (Kerr et al., 2012). A new global Level 3 
SSM dataset (referred to as SMOSL3; Jacquette et al., 2010) has been released very recently. The general principle of the algorithm is similar to the one used for producing the standard Level 2 SSM products, but the quality of the SSM product is enhanced by using multi-orbit retrievals (Kerr et al., 2013).

Another strategy to produce large-scale estimates of SM relies on modelling, either directly using multimodel SM means (Dirmeyer et al., 2006; Georgakakos \& Carpenter, 2006), or via assimilation systems, which aim at optimally combining land surface models and SM related observations (de Rosnay et al., 2012; Drusch \& Viterbo, 2007). This strategy has proved to be particularly fruitful and highlighted the need for accurate surface and root zone SM remotely sensed estimates (de Rosnay et al., 2011; de Rosnay et al., 2013; Draper et al., 2009a; MuñozSabater et al., 2007; Reichle et al., 2007). The SM-DAS-2 analysis, for instance, is retrieved by assimilating ASCAT SSM products in the ECMWF (European Centre for Medium-Range Weather Forecasts) Land Data Assimilation System, and the resulting estimates of SM benefit from high quality analysed atmospheric data (de Rosnay et al., 2011; de Rosnay et al., 2013;

Drusch et al., 2009).

Whatever their origin, the evaluation of global SSM products is needed to guide their correct use, and to improve our understanding of their strengths and weaknesses over a large spectrum of climate and environmental conditions across the world. Several studies have evaluated SSM products based on passive microwave sensors against in situ measurements and modelled data over different regions (Al Bitar et al., 2012; Albergel et al., 2012; Brocca et al., 2011; Dall'Amico et al., 2012; Draper et al., 2009a; Jackson et al., 2012; Lacava et al., 2012; Leroux et al., 2011; Mladenova et al., 2011; Sahoo et al., 2008; Su et al., 2011). Although consistent results were generally obtained from the remotely sensed and modelled data, disagreements or biases 
117 between the different sources of SSM data were noted depending on the particular regions or

118 time periods. For instance, Albergel et al. (2012) found that the SM-DAS-2 SSM estimates were

119 closer to in situ measurements in terms of correlation than SMOS and ASCAT SSM products, in

120 several stations situated in Africa, Australia, Europe, and the United States.

121

122

123

124

125

126

127

128

129

130

131

132

133

134

135

136

137

In this context, we present in this study a global evaluation of two SSM datasets retrieved from passive microwave observations (SMOSL3 and AMSRM, respectively based on SMOS and AMSR-E observations) against the SM-DAS-2 product, which is used here as a reference, because it is the most consistent SM product compared to in situ SM data (Albergel et al., 2012). In doing so, we have two specific objectives. The first objective is to provide the first assessment of the SMOSL3 product at global scale. The second objective is to compare SSM products retrieved from passive microwave observations at two different frequency bands: L-band $(\sim 1.4$ $\mathrm{GHz}$ ) for SMOSL3 vs. C-band ( $5 \mathrm{GHz})$ for AMSRM. Although the performances of L-band vs. C-band for SSM retrievals have been compared against experimental or simulated data sets (Calvet et al., 2011; Wigneron et al., 1993), no global study based on satellite data has yet been made, to our knowledge. L-band is generally considered to be the optimum frequency band for SM monitoring due to (i) lower attenuation effects by vegetation (ii) lower atmospheric effects and larger effective sampling depth $(\sim 0-3 \mathrm{~cm}$; Escorihuela et al., 2010$)$ than C-band.

The SSM datasets used and the methodology for their evaluation are described in Section 2. The results are then presented in Section 3. Finally, discussion and conclusions are given in Section 4.

\section{Materials and methods}




\subsection{Global-scale soil moisture datasets}

The main characteristics of the three SSM datasets considered in this study are summarized in Table 1. The evaluation was performed for the period 03/2010 - 09/2011, which corresponds to the full period of availability of the two satellite-based products: tests made during the SMOS commissioning phase ended in March 2010 while the AMSR-E spatial mission ended in October 2011.

\subsubsection{SMOSL3}

The SMOS satellite was launched in November 2009 and is operated by the European Space Agency (ESA), as part of its Living Planet Programme, and the Centre National d'Etudes Spatiales (CNES) in France. SMOS operates at L-band with a spatial resolution of 35-50 km (Kerr et al., 2010; Kerr et al., 2001). The SMOS mission aims to monitor SSM at a depth of about 3 to $5 \mathrm{~cm}$ and an accuracy of $0.04 \mathrm{~m}^{3} / \mathrm{m}^{3}$. SMOS provides global coverage with a 3-day revisit at the equator with a morning ascending orbit at 0600 hours local time and an afternoon descending orbit at 1800 hours (Kerr et al., 2012).

The CATDS Centre (Centre Aval de Traitement des Données; $\underline{\text { http://catds.ifremer.fr/) }}$ recently provided re-processed global maps of SSM at different temporal resolutions: daily products, 3 day global products insuring a complete coverage of the Earth surface, 10-day composite products, and monthly average products, the so-called SMOS level 3 products (SMOSL3). These products are presented in the NetCDF format on the EASE grid (Equal Area Scalable Earth grid) with a spatial resolution of $\sim 25 \mathrm{~km} \times 25 \mathrm{~km}$. The main principle of the algorithm used to retrieve SSM is the same as the one used by the ESA operational algorithm for producing the standard level 2 SSM products (Kerr et al., 2012; Wigneron et al., 2007). In both Level 2 (L2) and Level 3 
(L3) products, multiangular observations are used to retrieve simultaneously SSM and vegetation optical depth at nadir ( $\tau$-NAD) using a standard iterative minimization approach of a cost function (Statistical Inversion Approach as discussed in Wigneron et al. (2003)). The main difference with the $\mathrm{L} 2$ processing is the fact that the L3 processing takes into account over each pixel several revisits simultaneously in a multi-orbit retrieval approach (Jacquette et al., 2010; Kerr et al., 2013). In the L2 algorithm, SSM and $\tau$-NAD are retrieved from multiangular observations made using one SMOS overpass at 0600 or 1800 hours local time. Conversely, in the L3 algorithm, SSM and $\tau$-NAD are retrieved from multiangular observations made using several overpasses (3 at most) over a 7-day window. Over the short 7-day window, it is considered that optical depth at nadir ( $\tau$-NAD) varies slowly in time. In the L3 processor, this is accounted for by assuming that the retrieved values of $\tau$-NAD are correlated using a Gaussian auto-correlation function over the 7-day window (while the SM values are considered as uncorrelated). The multi-orbit retrieval approach was selected to produce the L3 product as it improves the SM retrieval (Kerr et al., 2013):

(i) Increasing the number of overpasses over a given node taking into account several revisits (multi-orbit approach) increases the number of observations available for a node. As the number of observations increases, more nodes are considered in the retrieval process, resulting in a larger coverage. This is mostly significant at the edge of the swath for which a single overpass does not provide enough brightness temperature (TB) data for an accurate retrieval process (Wigneron et al., 2000).

(ii) Considering that the vegetation optical thickness is correlated over a given period of time adds more constraints in the retrieval process and the robustness of the retrieval is improved. 
SMOSL3 (ascending and descending) datasets include flags that can be used to filter out the datasets (Jacquette et al., 2010; Kerr et al., 2013; Kerr et al., 2008). More details on the flags used to filter SMOSL3 data are given in Section 3.

Note that new versions of the SMOSL3 data set will be produced based on re-processing activities in the near future and will lead to improvements in the product accuracy. The version of SMOSL3 used in the present study was the latest version available at CATDS. The version of the processor is V2.48, corresponding to a Level-2 version higher than V5.0, although there is not a strict correspondence between Level-2 and Level-3 versions.

\subsubsection{AMSRM}

The Aqua satellite is operated by the National Aeronautics and Space Administration (NASA). It was launched in May-2002 and carries, among others, the AMSR-E radiometer providing passive microwave measurements at six frequencies $(6.925,10.65,18.7,23.8,36.5$, and 89.0 $\mathrm{GHz}$ ) with day-time ascending orbit at 1330 hours and night-time descending orbit at 0130 hours (Owe et al., 2008). The datasets cover the period from June 2002 to October 2011. On this latter date, AMSR-E on board the NASA Aqua satellite stopped producing data due to a problem with the rotation of its antenna.

The AMSR-E sensor was one of the first sensors to target SSM as a standard product (Njoku \& Chan, 2006; Njoku et al., 2003). Various algorithms have been developed to retrieve SSM from the AMSR-E observations. The main ones were developed at (i) NASA which produced the standard AMSR-E-NASA algorithm (Njoku et al., 2003), (ii) the Japan Aerospace Exploration Agency (Koike et al., 2004), and (iii) the "Vrije Universiteit Amsterdam" in collaboration with NASA, referred to as the NASA-VUA algorithm (Owe et al., 2008; Owe et al., 2001). The NASA-VUA algorithm uses a three-parameter retrieval approach (i.e., SSM, vegetation optical 
depth, and soil/canopy temperature are retrieved simultaneously) to convert multi-frequency TB measured by AMSR-E to SSM. The retrieved SSM products accuracy was shown to be 0.06 $\mathrm{m}^{3} / \mathrm{m}^{3}$ for sparsely to moderately vegetated canopies (de Jeu et al., 2008).

A range of studies (Brocca et al., 2011; Draper et al., 2009a; Hain et al., 2011; Rüdiger et al., 2009) addressed the evaluation of the NASA-VUA SSM products based on combinations of observations made at different AMSR-E frequencies, mainly using C-band $(6.925 \mathrm{GHz})$ and/or X-band $(10.65 \mathrm{GHz})$. Using in situ observations and/or modelled SM data as reference, these studies showed good performance of the NASA-VUA products in capturing the SSM variability at global scale.

In this paper a version (Level 3 gridded data) of the NASA-VUA product exclusively based on the AMSR-E C-band and descending orbit observations was used. It is referred hereafter to as AMSRM. Descending orbit (night time) SM products were shown in previous studies to be more accurate and less affected by temperature-related errors than ascending orbit (day time) products (Draper et al., 2009a; Jackson et al., 2010; Kerr \& Njoku, 1990; Su et al., 2011). The use of Cband $(6.925 \mathrm{GHz})$ data, i.e. the lowest frequency available for the AMSR-E instrument, maximises the soil sampling depth $(\sim 0-1 \mathrm{~cm})$ of the retrieved product (Owe et al., 2008) and minimises the sampling depth mismatch with the SMOSL3 product.

\subsubsection{ECMWF soil moisture analysis}

This study used the SM-DAS-2 SM analysis product as a reference. SM-DAS-2 is produced at ECMWF in the framework of the H-SAF project of EUMETSAT (Satellite Application Facility on support to operational Hydrology and water management; more information at http://hsaf.meteoam.it/). The SM-DAS-2 analysis uses the Hydrology Tiled ECMWF Scheme for Surface Exchanges over Land (HTESSEL; Balsamo et al., 2009; van den Hurk \& Viterbo, 2003). 
HTESSEL is a multilayer model where the soil is discretized in four layers (thickness: 7, 21, 72 and $189 \mathrm{~cm}$ ). SM-DAS-2 relies on a dedicated advanced Land Data Assimilation System: a simplified Extended Kalman Filter able to ingest information contained in observations close to the surface (temperature and relative humidity at 2 meters) as well as ASCAT SM retrieval (de Rosnay et al., 2013; Drusch et al., 2009), which is used to correct the model SM prognostic variable. SM-DAS-2 analysis is available at a spatial resolution of about $25 \mathrm{~km}$ (Gaussian reduced grid T799). The first layer $(0-7 \mathrm{~cm})$ is considered only, to represent the relatively low sampled soil layer of the SSM estimates derived from microwave remote sensing sensors $(\sim 0-3$ $\mathrm{cm}$ at L-band and $\sim 0-1 \mathrm{~cm}$ at C-band). SM-DAS-2 was shown to represent SM variability well. For instance, Albergel et al. (2012) have used in situ measurements from more than 200 stations located in western Africa, Australia, Europe, and the United States to determine the reliability of SM-DAS-2 to represent SM over 2010. Correlation values with in situ data were found to be very satisfactory over most of the investigated sites located in contrasted biomes and climate conditions with averaged correlation $(\mathrm{R})$ values of 0.70 and an estimate of the averaged error is about $0.07 \mathrm{~m}^{3} / \mathrm{m}^{3}$. SM-DAS-2 is produced in the framework of the H-SAF project from EUMETSAT and it benefits from the latest model and analysis developments from ECMWF. This is why it was selected as the benchmarking dataset for this study. However it is important to emphasize that, as shown by the validation statistics above, SM-DAS-2 does not represent the absolute truth. It was used as a reference in this paper because at the time of this study it was the product that best captures the SM dynamics. On the longer term, when the SM retrieval algorithms will be fully calibrated, it is likely that satellite products such as SMOS SM will be used as reference data sets for SM product comparison studies. SM-DAS-2 is a SM index product; however in this study it was converted to volumetric SM $\left(\right.$ in $\left.\mathrm{m}^{3} / \mathrm{m}^{3}\right)$ using global soil 
texture and hydraulic soil properties derived from the Food and Agriculture Organization digital (FAO) soil map as described in Balsamo et al. (2009). Hereafter, this product will be referred to as "DAS2".

\subsection{Pre-processing}

Quality control was applied to SMOSL3 and AMSRM prior to the evaluation based on quality flags associated with the remotely sensed datasets. The uncertainties associated with the NASAVUA retrieval algorithm are based on error propagation analysis, related to the sensor characteristics and vegetation optical depth, as described in Parinussa et al. (2011b). AMSRM SSM values with an estimated SSM uncertainty greater than $0.35 \mathrm{~m}^{3} / \mathrm{m}^{3}$ were rejected. Flags such as Data Quality IndeX (DQX) and Radio Frequency Interferences (RFI) are also associated with the SMOSL3 data and were used in our data selection. The DQX is an index related to the quality of the retrieved parameter. It takes into account the uncertainties associated with the parameter retrievals, depending on the number of multi-angular observations available, the surface conditions (dry or wet soil conditions, dense or sparse vegetation cover etc.), the TB accuracy, etc (Kerr et al., 2012; Wigneron et al., 2000). The DQX value is provided in volumetric SSM moisture units between 0 and $0.1 \mathrm{~m}^{3} / \mathrm{m}^{3}$. In this study, we selected data with a value of DQX lower than 0.06 , as we considered this ratio represents a good compromise between the need to keep sufficient data and the need to ensure data quality. Radio Frequency Interferences come from man-made emissions (e.g. satellite transmissions, aircraft communications, radar, TV radio-links, FM broadcast, and wireless camera monitoring systems). It perturbs the natural microwave emission emitted by the Earth surface and measured by passive microwave systems (Njoku et al., 2005; Oliva et al., 2012). With the SMOS interferometric system (based on a three arm Y-shaped antenna array), RFI effects are complex and oscillating 
interference effects may happen (Oliva et al., 2012). These effects could not be systematically detected and the SMOS L3 product is still contaminated by RFI effects. To illustrate the spatial patterns of the probability of RFI occurrences on SMOS observations, a map is given in Fig. 1. This map represents the three-year (i.e., 2010-2012) average of probability of RFI occurrences and shows the regions where the undetected RFI effects are the most likely. The RFI flags provided in the SMOSL3 data set are given in an attempt to filter out the most significant RFI effects. In the present study, SMOSL3 data were rejected if one of the following conditions was fulfilled:

(i) DQX $>0.06$ and DQX is equal to fill value (meaning the retrieval has failed),

(ii) Percentage of Radio Frequency Interference $\left(\mathrm{RFI}_{\text {fraction }}\right)>30 \%$, which is a daily RFI indicator, and

(iii) Probability of RFI $\left(\mathrm{RFI}_{\text {Prob }}\right)>30 \%$, which was computed from a moving window average of RFI events over several months.

Within the NASA-VUA algorithm for AMSR-E, Radio Frequency Interference is detected according to the method of Li et al. (2004). This method is based on absolute differences between the different frequencies. In the AMSRM product, the standard configuration of NASAVUA was used and C-band observations were used generally. Only when an RFI threshold value was reached, NASA-VUA made a switch to X band observations (Chung et al., 2013). Based on flags, AMSRM and SMOSL3 data were also rejected in regions of strong topography or wetlands. AMSRM, SMOSL3, and the reference DAS2 dataset were provided on different grids and formats. So pre-processing was required to allow a comparison of all products on the same grid. All the datasets were re-projected from their original coordinate systems onto a 
regular $0.25^{\circ} \times 0.25^{\circ}$ grid using a nearest neighbour approach (e.g., Draper et al., 2011; Rüdiger et al., 2009; Scipal et al., 2008).

\subsection{Comparison metrics}

Three statistical indicators were computed between pairs of the remotely sensed $\left(\mathrm{SSM}_{\mathrm{RS}}\right)$ and reference SSM products $\left(\mathrm{SSM}_{\mathrm{REF}}\right)$. We considered the Pearson correlation coefficient $(\mathrm{R})$, the mean difference (Bias), and the Root Mean Squared Difference (RMSD) between the remotely sensed $\left(\mathrm{SSM}_{\mathrm{RS}}\right)$ and the reference SM products. The equations for the calculation of the three indicators are given as follows (Brocca et al., 2011; CECR, 2012):

$$
R=\frac{\sum_{i=1}^{n}\left(\mathrm{SSM}_{\mathrm{REF}(\mathrm{i})}-\overline{\mathrm{SSM}_{\mathrm{REF}}}\right)\left(\mathrm{SSM}_{\mathrm{RS}(\mathrm{i})}-\overline{\left.\mathrm{SSM}_{\mathrm{RS}}\right)}\right.}{\sqrt{\sum_{i=1}^{n}\left(\mathrm{SSM}_{\mathrm{REF}(\mathrm{i})}-\overline{\mathrm{SSM}_{\mathrm{REF}}}\right)^{2} \sum_{i=1}^{n}\left(\mathrm{SSM}_{\mathrm{RS}(\mathrm{i})}-\overline{\mathrm{SSM}_{\mathrm{RS}}}\right)^{2}}}
$$

$$
\begin{gathered}
\text { Bias }=\frac{\overline{\left(\mathrm{SSM}_{\mathrm{RS}}-\mathrm{SSM}_{\mathrm{REF}}\right)}}{\text { RMSD }=\sqrt{\overline{\left(\mathrm{SSM}_{\mathrm{RS}}-\mathrm{SSM}_{\mathrm{REF}}\right)^{2}}}}
\end{gathered}
$$

Where the overbar denotes the mean operator, $\mathrm{n}$ is the number of SSM data, $\mathrm{SSM}_{\mathrm{RS}}$ is the satellite-based SSM product (SMOSL3 and AMSRM), and SSM $\mathrm{REF}_{\text {is }}$ is the reference SSM (DAS2). We used RMSD instead of RMSE (Root Mean Squared Error) because the reference SSM values may contain errors and cannot be considered as the "true" SSM values.

\subsection{Regional-scale analyses}

This regional study was made to compare the three different datasets for a variety of conditions. We compared the SSM time series from SMOSL3, AMSRM, and the reference (DAS2) over eight sites which were selected taking into consideration contrasting vegetation types and climate 
conditions (see Fig. 2). A summary of the main characteristics of the eight selected sites is given in Table 2. This evaluation was limited to only eight sites which cannot span the whole range of soil, vegetation, and climate conditions present at global scale. However, this evaluation allowed us to analyse and illustrate some major features of the three datasets. To compare the temporal dynamics of SSM between remotely sensed and reference observations, we removed the systematic differences by matching the remotely sensed time series to the reference time series as discussed by Dorigo et al. (2010). This was done by normalizing the original remotely sensed data (the data referred to as 'original' in the following are the data extracted directly from the SMOSL3 or AMSRM data set and expressed in volumetric units $\left(\mathrm{m}^{3} / \mathrm{m}^{3}\right) \mathrm{SSM}_{\mathrm{or}}$ so that they have the same mean and standard deviation as the reference SSM dataset $\mathrm{SSM}_{\mathrm{REF}}$ according to the following equation (Brocca et al., 2010; Draper et al., 2009a):

$$
\operatorname{SSM}(\mathrm{t})=\overline{\operatorname{SSM}_{\mathrm{REF}}}+\frac{\sigma\left(\mathrm{SSM}_{\mathrm{or}}\right)}{\sigma\left(\mathrm{SSM}_{\mathrm{REF}}\right)}\left(\operatorname{SSM}_{\mathrm{or}}(\mathrm{t})-\overline{\operatorname{SSM}_{\mathrm{or}}}\right)
$$

Here, $\operatorname{SSM}(t)$ stands for the rescaled remotely sensed retrievals at time steps $t=1, \ldots, n$, where $n$ is the total number of observations, $\overline{\operatorname{SSM}_{\mathrm{or}}}$ and $\sigma\left(\mathrm{SSM}_{\mathrm{or}}\right)$ are the mean and standard deviation of the original remotely sensed retrievals, respectively, and $\mathrm{SSM}_{\mathrm{REF}}$ and $\sigma\left(\mathrm{SSM}_{\mathrm{REF}}\right)$ are mean and standard deviation of the reference dataset, respectively.

\subsection{SSM seasonal anomalies}

All the above statistics were calculated for original SSM values, expressed in volumetric units $\left(\mathrm{m}^{3} / \mathrm{m}^{3}\right)$. We also applied the above performance metrics to SSM anomalies. The anomaly timeseries were calculated in order to avoid seasonal effects that can unrealistically increase the degree of correlation (Scipal et al., 2008) and to analyse the ability of remotely sensed SSM products to capture the day-to-day variability in the SSM time series. We computed the 
anomalies following the method described by Albergel et al. (2009). The anomalies $\operatorname{SSM}_{\text {anom }}(t)$ were computed as the difference to the mean for a sliding window of 35 days, which was further scaled using the standard deviation in order to be dimensionless:

$$
\operatorname{SSM}_{\text {anom }}(t)=\frac{\operatorname{SSM}_{\text {or }}(t)-\overline{\operatorname{SSM}_{\text {or }}(t-17: t+17)}}{\sigma\left[\operatorname{SSM}_{\text {or }}(t-17: t+17)\right]}
$$

where $S S M_{o r}(\mathrm{t})$ is the original SSM value at time t obtained from the satellite sensor or reference datasets, the over-bar and $\sigma$ symbols are the temporal mean and standard deviation operators, respectively, for a time window of 35 days corresponding to the time interval [ $\mathrm{t}-17$ days, $\mathrm{t}+17$ days]. The use of $\mathrm{a} \sim$ monthly window is a very common approach to compute SM anomalies (Brocca et al., 2011; Draper et al., 2013; Draper et al., 2009b; Reichle et al., 2008).

\subsection{Global-scale analyses}

Global maps of (i) correlations (R), to assess the global consistency in the SSM variability at both long- (original) and short-term (anomaly) scales, (ii) RMSD, and (iii) bias between the reference and the two remotely sensed SMOSL3 and AMSRM SSM time series were computed. The performance indicators were computed for all common pixels on a daily basis. To analyse the effects of the vegetation and climatic conditions and to facilitate the interpretation of the results of the global comparison, the values of the three performance indexes were averaged for a variety of biomes. These biomes represent different bioclimatic conditions and contrasting vegetation types. In this study we used the classification made by Chesworth (2008), illustrated in Fig. 2., who distinguished: "tundra", "boreal semi-humid", "boreal humid", "temperate semiarid", "temperate humid", "Mediterranean cold", "Mediterranean warm", "desert tropical", "desert temperate", "desert cold", and "tropical humid" biomes. 
The analysis of the results was also made accounting for the LAI (mean value computed over the pixel) to evaluate the link between the accuracy of the remotely sensed SSM products and the vegetation effects (in relation with vegetation density and biomass). To investigate this link, the global correlation results (original and anomalies) were averaged according to the global distribution of LAI values. The values of LAI were the long term-mean LAI values taken from the Global Soil Wetness Project (Dirmeyer et al., 2006) illustrated in Fig. 3.

\section{Results}

\subsection{Comparison of SMOSL3 ascending and descending overpasses}

Original SMOSL3 retrievals obtained from the ascending and descending overpasses were compared to the reference SSM data. In terms of correlation, a better performance of SMOSL3 for ascending orbits compared with descending orbits with respect to the reference can be clearly seen in Fig. 4. In much of the world (e.g., central USA, Europe, South America, and South Africa), ascending SMOSL3 retrievals were found to be better correlated to the reference datasets than descending SMOSL3 retrievals. This was expected because at dawn soil is often in near hydraulic equilibrium (Jackson, 1980), and factors affecting SM retrieval, such as vertical soil-vegetation temperature gradients, are minimized. In some places, however, particularly in India, Eastern USA, Eastern Australia, and the Middle East, descending SMOSL3 retrievals were found to be closer to the reference than the ascending ones. This result could be partly explained by the fact that ascending retrievals over these regions are highly affected by RFI (see Fig. 1), which is the main source of errors in the SMOS SSM products (Oliva et al., 2012). As the SMOS antenna is tilted forward by $32^{\circ}$, there is an asymmetry in the patterns of RFI contaminations between ascending and descending passes for a given ground location. For instance, when considering ascending overpasses over a given point in the Central Plains in the USA, the SMOS 
has a trajectory from South to North. And because the antenna is tilted by $32^{\circ}$ toward the North, it picks up RFI emission from the Defense Early Warning (DEW) system in Northern Canada (the DEW line can be seen through the lighter blue band around the USA-Canada border in Fig. 1). Conversely, for descending overpasses over the same sites, the tilted antenna is looking in a more southerly direction and is not contaminated by these northern RFI sites. To get a global assessment of the differences between the SSM retrievals for the ascending and descending overpasses, we computed the global averaged value of the RMSD and R coefficient between the SMOSL3 data and the reference; we obtained for ascending: $\mathrm{RMSD}=0.18 \mathrm{~m}^{3} / \mathrm{m}^{3}$ and $\mathrm{R}=0.44$ and for descending: $\mathrm{RMSD}=0.20 \mathrm{~m}^{3} / \mathrm{m}^{3}$ and $\mathrm{R}=0.41$. Given that better performances were generally found for ascending retrievals, only SMOSL3 ascending overpasses will be considered in the following.

\subsection{Comparison of the SSM time series over eight selected sites}

The time series of the three SSM products (SMOSL3, AMSRM, and DAS2) are compared in Fig. 5 for the eight selected sites described in Table 2. The SSM time series were spatially averaged over the whole site and normalized to have the same mean and standard deviation using the method given in Equation (4). The eight sites were selected to illustrate the SSM dynamics in the three products for a variety in vegetation, soil, and climatic conditions (see Fig. 2). In general, the seasonal dynamics of SSM for the three products were found to be similar. However, over the "tropical humid" site (Fig. 5a) the seasonal dynamic of the reference product is better reproduced by the SMOSL3 retrievals. Over this site, it can be seen that the seasonal trend in the AMSRM product is almost opposite to that of the two other products (SMOSL3 and DAS2): increasing trends in AMSRM correspond more or less to decreasing trends in both SMOSL3 and DAS2 and vice versa. Over the same site, it can be seen that there is a large 
413 plateau ( six months from October to April) in the DAS2 values, which cannot be seen for the 414 two other products.

415 Over the site in India (Fig. 5b), a plateau for high values of SSM during the monsoon season can 416 also be seen for DAS2 and not for SMOSL3 and AMSRM, but it is shorter ( $\sim$ three months) than

417

418 over the site in the "tropical humid" biome. Also, the transition from wet to dry conditions after the monsoon season is more abrupt for DAS2 than for the remotely sensed SSM values. Over this region, ascending SMOSL3 data are highly impacted by RFI from Northern India and surrounding countries (see Fig. 1) but they still reproduce a SSM dynamic, which is in good agreement with the AMSRM and DAS2 datasets.

The site in Central Australia (Fig. 5c), is a desert area which has the advantage of being almost free of RFI contaminations at both L- (see Fig. 1) and C-bands (Njoku et al., 2005) along with low vegetation and unfrozen conditions in general. In this area, both SMOSL3 and AMSRM were found to be very close to the reference and the very dry conditions were well depicted. There is generally good agreement between all three products in the detection of rain events over this desert area. It should be noted that during the wet season (May, June, July), the declining trend in the SSM time series based on SMOSL3 and DAS2 seems to be slightly steeper than the one retrieved from AMSRM. Also, during rain events, very high values of SSM can be seen for SMOSL3. Such results have already been noted in previous studies and could be explained by water ponding effects when soil is at saturation during intensive rain events (Al Bitar et al., 2012; Jackson et al., 2012; Wigneron et al., 2012).

Over the two sites in the USA (Figs. 5d and 5e), and in the Sahel (Fig. 5f), there is generally good agreement between the three SSM products, but it can be clearly seen that there is a much larger scatter in the remotely sensed products than in the reference one (DAS2). During cold 
periods in the Great Basin Region in the USA (Fig. 5d) very low values can be seen (below 0.1 $\mathrm{m}^{3} / \mathrm{m}^{3}$ ). These values can be explained by the effect of soil freezing. In DAS2, the SSM values do not account for the frozen soil water content and its SSM estimates correspond only to the liquid soil water content. These peak values corresponding to "very dry conditions" cannot be seen in SMOSL3 and AMSRM, as frozen soil conditions were flagged and excluded in the remotely sensed products. In the site in Sahel (Fig. 4f), there is quite a good agreement between the general seasonal trends of all three SSM products. However, some outliers can be noted for AMSRM, especially when it rains and at the end of the wet season, and the scatter in the SMOSL3 dataset is much larger than that of the two other products.

Finally, results for two sites in wet regions are illustrated in Fig. 5g (Central Europe) and Fig. 5h (Argentina). Even if the seasonal trend is relatively low over these two sites (SSM varying between 0.3 and $0.4 \mathrm{~m}^{3} / \mathrm{m}^{3}$ ), it can be seen that there is good general agreement between all three products. As was found in some previous figures, very high values in SMOSL3 SSM data can be seen in Fig. $5 \mathrm{~g}$ during some rain events and very low values corresponding to freezing conditions can be seen in Fig. 5h for DAS2. In summary, all the three products behaved similarly over the different test sites considered in this study, each product having in some cases some caveats either irregular behaviour or adversely affected by RFI effects.

\subsection{Spatial Analysis of SSM retrievals at Global Scale}

To get a more global evaluation of the SMOSL3 and AMSRM products, maps of the calculated statistical indicators (Correlation coefficient (R) for both original SSM values and anomalies, RMSD and Bias) described in section 3.2 are shown in Figs. 6a-h at global scale. In these maps, SMOSL3 and AMSRM were evaluated against the reference dataset (DAS2) for the period 03/2010-09/2011 and only significant correlations are presented. In this study, we consider that 
the correlation is statistically significant when the p-value is less than the significance level of 0.05 (p-value $<0.05$ meaning that the probability of observing such a correlation value by chance is lower than 5\%) as considered in several studies in this field (Albergel et al., 2012). In general, it can be seen that the three products have similar spatial patterns over most of the globe, although there are important differences between them in the amplitude of the temporal SSM variations. Figs. $6 \mathrm{a}$ and $6 \mathrm{~b}$ show that robust correlations between the global remotely sensed and the reference SSM products $(\mathrm{R}>0.5)$ were found in the transition zones between wet and dry climates (e.g., Sahel), in the Great Plains (USA), Western Europe, Eastern Australia, India, South Africa, and the south-eastern region of Brazil. This can be explained by the strong seasonal annual cycle of SSM in these regions

(Koster et al., 2004a). Conversely, remotely sensed datasets exhibited weak correlations (R < 0.20) against the reference in arid regions (e.g., Sahara) due to the small range of variation in the SSM values, which corresponds roughly to the remotely sensed retrieval accuracy $(\sim 0.04$ $\mathrm{m}^{3} / \mathrm{m}^{3}$ ). Low correlations in high latitude regions can also be seen in Fig. 6a and b, where correlations values $(\mathrm{R})$ drop below 0.25 . The significant differences between satellites and model products in high latitude regions may partly be explained by the effect of frozen soil conditions. Correlation values (R) computed on seasonal anomalies, as described in section 3.4, are shown in Fig. $6 \mathrm{c}$ and $6 \mathrm{~d}$. It can be seen that the global spatial patterns are relatively similar for both SMOSL3 and AMSRM, with better ability of SMOSL3 to capture the short-term SM variability than AMSRM. The highest values of the R coefficient were found in eastern Australia, extreme South Africa, Western Europe, and Central America while the lowest values were found in the northern tundra region. 
A similar distribution of RMSD and bias values was found for both SMOSL3 and AMSRM products (Figs. 6e-h). Low RMSD and bias values were found in deserts and semi-arid regions (e.g., the Sahara, the Arabian Peninsula, extreme South Africa, and central Australia), while high RMSD and bias values were found in high latitude regions (e.g., in Northern Canada, Alaska, Northern Europe, and Siberia). Large differences between the remotely sensed and the reference SSM products were also found in tropical regions. In Figs. $6 \mathrm{~g}$ and $6 \mathrm{~h}$, relatively similar patterns can be noted for both SMOSL3 and AMSRM at global scale but the values of the biases are quite different: a strong overestimation of the reference SSM values can be noted for AMSRM, especially in the high latitude and desert regions, while a strong underestimation can be noted for SMOSL3.

To better identify the spatial differences in the results obtained for SMOSL3 and AMSRM, Fig. $7 \mathrm{a}$ and $7 \mathrm{~b}$ show the areas where SMOSL3 correlates better with the reference than AMSRM (red), where AMSRM correlates better with the reference than SMOSL3 (green) and where the difference in the correlation coefficient (R) between both SMOSL3 and AMSRM is less than 0.05 (blue). The top panel shows results for the original SSM datasets, while the bottom panel shows results for anomalies, i.e. areas where either SMOSL3 or AMSRM better captured the short-term variability in the reference SSM values. In these maps only significant values are plotted (p-value $<0.05$ ). In general, it can be seen that better correlations with DAS2 were obtained with SMOSL3 over regions with high to moderate vegetation density (e.g., in parts of Amazonia, Eastern Australia and the North-Central US). These latter regions are known to be little contaminated by RFI effects (see Fig. 1). On the other hand, it can be seen that AMSRM shows better correlations with DAS2 than SMOSL3 in areas with low to moderate vegetation density and where there is a strong seasonality in the SSM variability (e.g., India, Western 
Australia, Sahara, and Arabian Peninsula). Poor results were also obtained systematically for SMOSL3 in regions known to be strongly contaminated by RFI effects (Middle East, Southern Europe, China, and India).

When looking at anomalies, AMSRM and SMOSL3 have relatively similar performances over dry regions, but better correlations with the reference were obtained for SMOSL3 over most of the grid cells.

\subsection{Biome influence}

To investigate more in depth the dependence of the results shown in Fig. 6 and Fig. 7 on the vegetation and climatic conditions, the statistical indicators were averaged for the twelve types of biomes described in Section 3.5 and illustrated in Fig. 2. The results are shown in Figs. 8a-d in terms of correlation (R) for original SSM data and anomalies, RMSD, and bias.

The distributions of the correlation (R) and RMSD values as a function of biome types are quite similar for both SMOSL3 and AMRSM (Figs. 8a-c). In terms of correlation values computed from the original SSM data (Fig. 8a), the best results were obtained for biomes with relatively sparse vegetation covers ("Mediterranean warm", "Mediterranean cold", "temperate semi-arid", "tropical semi-arid", etc.), while the poorest results were found in Northern environments ("tundra", "boreal semi-arid", and "boreal humid"). Yet, the results are quite different for the "Tropical humid" biome, where performances of SMOSL3 were more coherent with DAS2 (R= 0.42) compared to the results found for AMSRM $(\mathrm{R}=0.15)$.

Fig. $8 \mathrm{~b}$ shows that the mean correlation coefficients computed from the SSM anomalies are lower than the mean correlation coefficients computed from the original SSM, as the covariations imposed on all three datasets by the seasonal forcing are largely filtered out in SSM anomalies. The general pattern of the distribution of the $\mathrm{R}$ values as a function of the biomes is 
similar to the one obtained for the original SSM data. It seems that the short-term variability in the SSM values is better detected by SMOSL3: better performances were obtained for SMOSL3 over all biomes, even if the correlation values are relatively small.

In Fig. 8c, confirming previous results, the poorest performances (corresponding to the largest RMSD values), were obtained again in Northern environments ("tundra", "boreal semi-arid, and "boreal humid") for both SMOSL3 and AMSRM, while the best results (smallest RMSD values) were obtained in desert regions ("desert temperate", "desert tropical”) and in semi-arid regions. As discussed previously, in desert areas, the range in the SSM values simulated in DAS2 is relatively small and this fact partly explains the low values of RMSD computed.

Finally, Fig. 8d shows that biases with respect to the reference dataset are opposite for SMOSL3 and AMSRM. In all biomes, AMSRM overestimates SSM DAS2 values while SMOSL3 underestimates them. Moreover, the bias between remotely sensed and reference SSM varies substantially across biomes. The bias is very large in northern environments for both SMOSL3 and AMSRM but it is also large in humid regions ("temperate humid", "tropical humid") for SMOSL3. The lowest biases were found in deserts ("desert temperate", "desert tropical", and "desert cold") and in semi-arid regions ("temperate semi-arid", "Mediterranean warm" and "Mediterranean cold") for both SMOSL3 and AMSRM.

\subsection{Influence of leaf area index (LAI)}

Previous results showed that vegetation plays a key role in the performance results of the SMOSL3 and AMSRM products. To analyse in more detail the effect of vegetation, we computed the distribution of the correlation values as a function of the LAI. We chose to focus our study on the R correlation indicator as correlation is of particular interest for many hydrologic and atmospheric applications (Koster et al., 2009). In Figs. 9a and 9b, the correlation 
values shown in Fig. $6 \mathrm{a}$ and $6 \mathrm{~b}$ (for original and anomaly SSM data) were averaged according to the values of LAI illustrated in the global map shown in Fig. 3. The results for both original SSM data (Fig. 9a) and anomalies (Fig. 9b) show that the performance of the remotely sensed SSM products (i.e., SMOSL3 and AMRSM) is strongly related to the distribution of the LAI values. In Fig. 9a, it can be seen that the values of the correlation coefficient (R) decrease almost linearly with the mean value of LAI for both SMOSL3 and AMSRM. The rate of the decrease is much larger for AMSRM than for SMOSL3. For AMSRM the value of $\mathrm{R}$ decreases from $\mathrm{R} \approx 0.45$ to negative correlation values $(\mathrm{R} \approx-0.1)$ as LAI increased from about 1 to 7 . For the same increase in $\mathrm{LAI}$ values, the decrease in $\mathrm{R}$ for SMOSL3 is more limited: from $\mathrm{R} \approx 0.4$ to $\mathrm{R} \approx 0.3$. However, it should be noted that AMSRM provides slightly better performances than SMOSL3 when LAI is lower than 1 (i.e. over sparse vegetation covers), which corresponds to almost $50 \%$ of the pixels considered in this global analysis.

In Fig. 9b, the same analysis is shown for anomalies. It can be seen that better performances were obtained for SMOSL3, whatever the range of LAI values. Moreover, for this latter product, the correlation values remain stable $(\mathrm{R} \approx 0.3)$ as LAI values increase. Conversely, the values of the $\mathrm{R}$ coefficient decrease rapidly and continuously for AMSMR as LAI values increase: $\mathrm{R} \approx$ 0.25 for $\mathrm{LAI} \approx 1$ down to $\mathrm{R} \approx 0.03$ for $\mathrm{LAI} \approx 7$.

\section{Discussion and conclusions}

This study investigated the performances of two remotely sensed SSM products (SMOSL3 and AMSRM) with respect to a reference SSM product (DAS2) at global scale, with $0.25^{\circ}$ spatial sampling and a daily time step. The study was made during the whole period of common 
availability of the SMOS and AMSR-E products, i.e. after the test periods during the commissioning phase of SMOS and before AMSR-E stopped producing data (03/2010-09/2011). Both AMSRM and SMOSL3 generally showed a good agreement with the reference dataset and successfully captured the seasonal SSM variations present in the reference DAS2 product. For instance, SMOSL3 and AMSRM performed well (in terms of correlation) in the transition zones between wet and dry climates and over semi-arid regions (e.g., Indian subcontinent, Great Plains of North America, Sahel, Eastern Australia, and South-eastern regions of Brazil). It is particularly important that the two remotely sensed SSM products being compared give consistent and correct results in these areas, where SM has been recognized to exert a strong influence on the weather/climate (e.g., Koster et al., 2004a; Taylor et al., 2012; Teuling et al., 2010). Conversely, both SMOSL3 and AMSRM exhibited weak correlations with the reference data in dry regions (e.g. Sahara, Arabian Peninsula, and central Australia). These results could be related to the low range of variations in SSM in these regions, which roughly corresponds to the expected retrieval accuracy of the remotely sensed products $\left(\sim 0.04 \mathrm{~m}^{3} / \mathrm{m}^{3}\right)$.

We found quite opposite results in terms of bias for SMOSL3 and AMSRM: over all biomes, AMSRM overestimated SSM compared to the reference, while SMOSL3 underestimated SSM. The analysis of the SSM anomaly time series, obtained by removing the seasonal cycle, showed that the short-term SSM dynamics were better captured by SMOSL3 than by AMSRM at global scale. In addition, considering a variety of biomes, both SMOSL3 and AMSRM showed lowest performances in northern environments ("tundra", "boreal semi-arid", and "boreal humid"), while the best performances were found over biomes with relatively sparse vegetation covers ("Mediterranean warm", "Mediterranean cold", "temperate semi-arid", "tropical semi-arid", 
etc.). In the "tropical humid" biome, SMOSL3 was found to be much better correlated to DAS2 than AMSRM.

The results confirmed that vegetation plays a key role in the performance evaluation of the SMOSL3 and AMSRM SSM products. Over areas with sparse vegetation, with LAI values lower than 1, both SMOSL3 and AMSRM had relatively good and similar performances. However, for higher LAI values, SMOSL3 had a consistent performance, whereas the performance of AMSRM quickly deteriorated with the increase in foliar abundance.

The fact that better performances could be obtained with SMOS (operating at L-band) than with AMSR-E (operating at C-band) over vegetated areas is not surprising. However this study presents one of the first studies confirming this effect with observations from sensors in space. In the passive microwave domain, L-band has long been considered as an optimal frequency to monitor SSM. When a vegetation layer is present over the soil surface, it attenuates the soil emissions and adds its own contribution to the emitted radiation measured by passive microwave radiometers. The retrieval algorithm attempts to decouple the effects of soil and vegetation in order to provide an estimation of SSM. However, as vegetation effects increase with increasing frequency (Calvet et al., 2011), the correction for vegetation effects is more complex at C-band ( $\sim 6.6 \mathrm{GHz}$ for AMSR-E) than at L-band ( $1.4 \mathrm{GHz}$ for SMOS). Moreover, SMOS has multiangular capabilities which make it, theoretically, more efficient for decoupling the soil and vegetation effects than mono-angular spatial radiometers such as AMSR-E (Wigneron et al., 2000). The combination of both a L-band system and multi-angular capabilities for SMOS compared to a C-band system and monoangular capabilities for AMSR-E might explain the better performance of SMOS over biomes with dense vegetation cover (e.g., "tropical humid") in Figs. $8 \mathrm{a}$ and $8 \mathrm{~b}$ or for LAI values larger than 1 in Figs $9 \mathrm{a}$ and $9 \mathrm{~b}$. However, it should be noted 
that AMSRM had comparable performances to SMOSL3 (better performances if we consider the original SSM data and slightly lower performances if we consider anomalies) over sparse vegetation covers (with $\mathrm{LAI} \leq 1$ ), which represent more than $50 \%$ of the pixels considered in this global study. Future works will address in more depth the possibilities to exploit the complementary capabilities of both SMOS and AMRS-E to retrieve SSM over a gradient of vegetation density and to produce a coherent long term SSM product based on passive microwave sensors.

Some other aspects should be considered in this evaluation. As noted in the Introduction, the effective SM sampling depth at L-band $(\sim 0-3 \mathrm{~cm})$ is larger than at C-band $(\sim 0-1 \mathrm{~cm})$. Over a shallower soil layer $(0-1 \mathrm{~cm}) \mathrm{SSM}$ is more prone to quick time variations, especially during drying-out periods, due to weather events (rainfall, wind, high insolation, etc.) than over deeper soils. This effect may lead to lower correlations with SSM measurements or retrievals, which are not made at the exact same time or over larger soil sampling depth. Moreover, in the present study, the sampling depth corresponding to the SMOSL3 SSM product $(\sim 0-3 \mathrm{~cm})$ is closer to that of the reference (0-7 $\mathrm{cm}$ for DAS2), than the sampling depth of AMRSM. Therefore, the mismatch between the sampling depths of the different products considered in this study is more detrimental for AMRSM, though it is present for both satellite data sets.

The effect due to the mismatch between the sampling depths of the different products may have an impact in the statistical indicators used in this study but it cannot fully explain the large and contrasting biases found between both the AMRSM and SMOSL3 products and the DAS2 reference. The positive bias in the AMSRM retrievals can be partially explained by the absence of correction in the NASA-VUA algorithm for open water bodies. It can also be caused by a wrong estimation of the effective temperature in NASA-VUA algorithm over northern regions, 
leading to positive bias in satellite retrievals (Owe et al., 2008). In contrast, the negative bias found in SMOSL3 is consistent with the results obtained in previous studies (Al Bitar et al., 2012; Albergel et al., 2012; Dall'Amico et al., 2012; Jackson et al., 2012; Lacava et al., 2012; Sanchez et al., 2012) comparing SMOS retrievals with in situ measurement networks in different regions of the world which all relied on the first release of the SMOS retrieval algorithm. RFI may increase the brightness temperatures (TB) measured by SMOS, leading to smaller retrieved SSM values and, thus, to a negative bias (Oliva et al., 2012). However, Wigneron et al. (2012) showed that, even though no bias could be observed in the measured TB data over the VAS site in Spain, a strong negative bias could be noted in the SMOS SSM retrievals. Thus, the negative bias found in the SMOS SSM products (Fig. 8d) is likely to be related to some issues in the retrieval algorithm (e.g., accounting for pixel heterogeneity, use of auxiliary data, etc.) or in the L-MEB (L-band Microwave Emission of the Biosphere) forward modelling. For instance, recent results showed that the use of the dielectric soil model developed by Mironov et al. (2012), instead of the model of Dobson et al. (1985) led to improved results (the bias decreased by about $0.04 \mathrm{~m}^{3} / \mathrm{m}^{3}$ at global scale) and the New L2 SSM shows almost no negative bias. Moreover, improvements will be made by better accounting for the effects of litter, surface roughness, effective soil temperature, etc. (Grant et al., 2007; Saleh et al., 2009).

Finally, it should be noted that even though the reference product used in this study (SM-DAS-2 from ECMWF) was found to be very reliable according to some recent studies (Albergel et al., 2012), estimates of SSM from LDAS cannot be considered as "ground truth" (Albergel et al., 2013). One must keep in mind that when using them to evaluate other SSM products, the interpretation of the results is hampered by their own accuracy (the accuracy of LDAS itself and its required inputs such as the atmospheric forcing, observations, etc.). For instance, Albergel et 
al. (2012) pointed out some non-realistic representation of SM in ECMWF products in some regions of the world (e.g. the Tibetan plateau), due to shortcomings in the description of soil characteristics, in the pedotransfer functions employed, and the difficulty of representing soil spatial heterogeneity.

\section{Acknowledgments}

The authors would like to thank the two anonymous reviewers for their helpful comments and the TOSCA (Terre Océan Surfaces Continentales et Atmosphère) CNES program and the Islamic Development Bank (IDB) for funding this research work. The authors acknowledge CATDS for the SMOSL3 dataset (http://catds.ifremer.fr) and the EUMETSAT Satellite Application Facility (SAF) on support to operational hydrology and water management (H-SAF) for the SM-DAS-2 product. The authors also wish to thank the whole SMOS team at CESBIO for fruitful discussions. We are also grateful to Mr Christophe Moisy for providing valuable technical assistance and to Dr Barry Gardiner for revising the English of the manuscript.

\section{References}

Al Bitar, A., Leroux, D., Kerr, Y.H., Merlin, O., Richaume, P., Sahoo, A. \& Wood, E.F. (2012). Evaluation of SMOS Soil Moisture Products Over Continental U.S. Using the SCAN/SNOTEL Network. Geoscience and Remote Sensing, IEEE Transactions on, 50, $1572-1586$

Albergel, C., de Rosnay, P., Gruhier, C., Munoz-Sabater, J., Hasenauer, S., Isaksen, L., Kerr, Y. \& Wagner, W. (2012). Evaluation of remotely sensed and modelled soil moisture products using global ground-based in situ observations. Remote Sensing of Environment, $118,215-226$

Albergel, C., Dorigo, W., Balsamo, G., Muñoz-Sabater, J., de Rosnay, P., Isaksen, L., Brocca, L., de Jeu, R. \& Wagner, W. (2013). Monitoring multi-decadal satellite earth observation 
of soil moisture products through land surface reanalyses. Remote Sensing of Environment, 138, 77-89

Albergel, C., Rüdiger, C., Carrer, D., Calvet, J.-C., Fritz, N., Naeimi, V., Bartalis, Z. \& Hasenauer, S. (2009). An evaluation of ASCAT surface soil moisture products with insitu observations in Southwestern France. Hydrology and Earth System Sciences, 13

Balsamo, G., Viterbo, P., Beljaars, A.C.M., van den Hurk, B.J.J.M., Hirschi, M., Betts, A.K. \& K., S. (2009). A revised hydrology for the ECMWF model: Verification from field site to terrestrial water storage and impact in the ECMWF-IFS. J. Hydrometeor, 10

Bartalis, Z., Wagner, W., Naeimi, V., Hasenauer, S., Scipal, K., Bonekamp, H., Figa, J. \& Anderson, C. (2007). Initial soil moisture retrievals from the METOP-A Advanced Scatterometer (ASCAT). Geophysical Research Letters, 34, L20401

Beljaars, A.C.M., Viterbo, P., Miller, M.J. \& Betts, A.K. (1996). The Anomalous Rainfall over the United States during July 1993: Sensitivity to Land Surface Parameterization and Soil Moisture Anomalies. Monthly Weather Review, 124, 362-383

Bindlish, R., Jackson, T.J., Wood, E., Gao, H., Starks, P., Bosch, D. \& Lakshmi, V. (2003). Soil moisture estimates from TRMM Microwave Imager observations over the Southern United States. Remote Sensing of Environment, 85, 507-515

Bolten, J.D., Crow, W.T., Xiwu, Z., Jackson, T.J. \& Reynolds, C.A. (2010). Evaluating the Utility of Remotely Sensed Soil Moisture Retrievals for Operational Agricultural Drought Monitoring. Selected Topics in Applied Earth Observations and Remote Sensing, IEEE Journal of, 3, 57-66

Brocca, L., Hasenauer, S., Lacava, T., Melone, F., Moramarco, T., Wagner, W., Dorigo, W., Matgen, P., Martínez-Fernández, J., Llorens, P., Latron, J., Martin, C. \& Bittelli, M. (2011). Soil moisture estimation through ASCAT and AMSR-E sensors: An intercomparison and validation study across Europe. Remote Sensing of Environment, $115,3390-3408$

Brocca, L., Melone, F., Moramarco, T., Wagner, W. \& Hasenauer, S. (2010). ASCAT soil wetness index validation through in situ and modeled soil moisture data in central Italy. Remote Sensing of Environment, 114, 2745-2755

Calvet, J.C., Wigneron, J.P., Walker, J., Karbou, F., Chanzy, A. \& Albergel, C. (2011). Sensitivity of Passive Microwave Observations to Soil Moisture and Vegetation Water Content: L-Band to W-Band. Geoscience and Remote Sensing, IEEE Transactions on, 49, 1190-1199

CECR (2012). Comprehensive Error Characterisation Report, Version 0.7. ESA Climate Change Initiative Phase 1 Soil Moisture Project

Cheruy, F., Campoy, A., Dupont, J.C., Ducharne, A., Hourdin, F., Haeffelin, M., Chiriaco, M. \& Idelkadi, A. (2013). Combined influence of atmospheric physics and soil hydrology on the simulated meteorology at the SIRTA atmospheric observatory. Climate Dynamics, 40, 2251-2269

Chesworth, W. (2008). Biomes and their Soils. In W. Chesworth (Ed.), Encyclopedia of Soil Science (pp. 61-68): Springer Netherlands

Chung, D., de Jeu, R.A.M., Dorigo, W., Hahn, S., Melzer, T. \& Parinussa, R.M.e.a. (2013). ESA CCI soil moisture algorithm theoretical baseline document version, 1, 36-44

Dall'Amico, J.T., Schlenz, F., Loew, A. \& Mauser, W. (2012). First Results of SMOS Soil Moisture Validation in the Upper Danube Catchment. Geoscience and Remote Sensing, IEEE Transactions on, 50, 1507-1516 
Daly, E. \& Porporato, A. (2005). A review of soil moisture dynamics: from rainfall infiltration to ecosystem response. Environ Eng Sci 22(1), 9-24

de Jeu, R.A.M., Wagner, W., Holmes, T.R.H., Dolman, A.J., Giesen, N.C. \& Friesen, J. (2008). Global Soil Moisture Patterns Observed by Space Borne Microwave Radiometers and Scatterometers. Surveys in Geophysics, 29, 399-420

De Lannoy, G.J.M., Reichle, R.H. \& Pauwels, V.R.N. (2013). Global Calibration of the GEOS-5 L-Band Microwave Radiative Transfer Model over Nonfrozen Land Using SMOS Observations. Journal of Hydrometeorology, 14, 765-785

de Rosnay, P., Balsamo, G., Albergel, C., Muñoz-Sabater, J. \& Isaksen, L. (2012). Initialisation of Land Surface Variables for Numerical Weather Prediction. Surveys in Geophysics, 115

de Rosnay, P., Drusch, M., Balsamo, G., Isaksen, L. \& Albergel, C. (2011). Extended Kalman Filter soil moisture analysis in the IFS. ECMWF Spring Newsletter $n 127$

de Rosnay, P., Drusch, M., Vasiljevic, D., Balsamo, G., Albergel, C. \& Isaksen, L. (2013). A simplified Extended Kalman Filter for the global operational soil moisture analysis at ECMWF. Quarterly Journal of the Royal Meteorological Society, 139, 1199-1213

Dirmeyer, P.A., Gao, X., Zhao, M., Zhichang, G., Oki, T. \& Hanasaki, N. (2006). GSWP $\neg$ 2: Multimodel analysis and implications for our perception of the land surface. B. Am. Meteorol, 87

Dobriyal, P., Qureshi, A., Badola, R. \& Hussain, S.A. (2012). A review of the methods available for estimating soil moisture and its implications for water resource management. Journal of Hydrology, 458-459, 110-117

Dobson, M.C., Ulaby, F.T., Hallikainen, M.T. \& El-Rayes, M.A. (1985). Microwave Dielectric Behavior of Wet Soil-Part II: Dielectric Mixing Models. Geoscience and Remote Sensing, IEEE Transactions on, GE-23, 35-46

Dorigo, W.A., Scipal, K., Parinussa, R.M., Liu, Y.Y., Wagner, W., de Jeu, R.A.M. \& Naeimi, V. (2010). Error characterisation of global active and passive microwave soil moisture datasets. Hydrol. Earth Syst. Sci., 14, 2605-2616

Dorigo, W.A., Wagner, W., Hohensinn, R., Hahn, S., Paulik, C., Drusch, M., Mecklenburg, S., van Oevelen, P., Robock, A. \& Jackson, T. (2011). The International Soil Moisture Network: a data hosting facility for global in situ soil moisture measurements. Hydrol. Earth Syst. Sci. Discuss., 8

Draper, C., Mahfouf, J.F., Calvet, J.C., Martin, E. \& Wagner, W. (2011). Assimilation of ASCAT near-surface soil moisture into the SIM hydrological model over France. Hydrol. Earth Syst. Sci., 15, 3829-3841

Draper, C., Reichle, R., de Jeu, R., Naeimi, V., Parinussa, R. \& Wagner, W. (2013). Estimating root mean square errors in remotely sensed soil moisture over continental scale domains. Remote Sensing of Environment, 137, 288-298

Draper, C.S., Mahfouf, J.F. \& Walker, J.P. (2009a). An EKF assimilation of AMSR-E soil moisture into the ISBA land surface scheme. Journal of Geophysical Research: Atmospheres, 114, D20104

Draper, C.S., Walker, J.P., Steinle, P.J., de Jeu, R.A.M. \& Holmes, T.R.H. (2009b). An evaluation of AMSR-E derived soil moisture over Australia. Remote Sensing of Environment, 113, 703-710 
Drusch, M., Scipal, K., de Rosnay, P., Balsamo, G., Andersson, E., Bougeault, P. \& Viterbo, P. (2009). Towards a Kalman Filter based soil moisture analysis system for the operational ECMWF Integrated Forecast System. Geophysical Research Letters, 36, L10401

Drusch, M. \& Viterbo, P. (2007). Assimilation of Screen-Level Variables in ECMWF's Integrated Forecast System: A Study on the Impact on the Forecast Quality and Analyzed Soil Moisture. Monthly Weather Review, 135, 300-314

Entekhabi, D., Njoku, E.G., O'Neill, P.E., Kellogg, K.H., Crow, W.T., Edelstein, W.N., Entin, J.K., Goodman, S.D., Jackson, T.J., Johnson, J., Kimball, J., Piepmeier, J.R., Koster, R.D., Martin, N., McDonald, K.C., Moghaddam, M., Moran, S., Reichle, R., Shi, J.C., Spencer, M.W., Thurman, S.W., Leung, T. \& Van Zyl, J. (2010). The Soil Moisture Active Passive (SMAP) Mission. Proceedings of the IEEE, 98, 704-716

Entekhabi, D., Rodriguez-Iturbe, I. \& Castelli, F. (1996). Mutual interaction of soil moisture state and atmospheric processes. Journal of Hydrology, 184, 3-17

Escorihuela, M.J., Chanzy, A., Wigneron, J.P. \& Kerr, Y.H. (2010). Effective soil moisture sampling depth of L-band radiometry: A case study. Remote Sensing of Environment, 114, 995-1001

Gao, H., Wood, E.F., Jackson, T.J., Drusch, M. \& Bindlish, R. (2006). Using TRMM/TMI to Retrieve Surface Soil Moisture over the Southern United States from 1998 to 2002. Journal of Hydrometeorology, 7, 23-38

Georgakakos, K.P. \& Carpenter, T.M. (2006). Potential value of operationally available and spatially distributed ensemble soil water estimates for agriculture. Journal of Hydrology, $328,177-191$

Grant, J.P., Wigneron, J.P., Van de Griend, A.A., Kruszewski, A., Søbjærg, S.S. \& Skou, N. (2007). A field experiment on microwave forest radiometry: L-band signal behaviour for varying conditions of surface wetness. Remote Sensing of Environment, 109, 10-19

Hain, C.R., Crow, W.T., Mecikalski, J.R., Anderson, M.C. \& Holmes, T. (2011). An intercomparison of available soil moisture estimates from thermal infrared and passive microwave remote sensing and land surface modeling. Journal of Geophysical Research: Atmospheres, 116, D15107

Hollinger, S.E. \& Isard, S.A. (1994). A Soil Moisture Climatology of Illinois. Journal of Climate, 7

Jackson, T.J. (1980). Profile soil moisture from surface measurements. Journal of the Irrigation and Drainage Division of the ASCE, 106

Jackson, T.J., Bindlish, R., Cosh, M.H., Tianjie, Z., Starks, P.J., Bosch, D.D., Seyfried, M., Moran, M.S., Goodrich, D.C., Kerr, Y.H. \& Leroux, D. (2012). Validation of Soil Moisture and Ocean Salinity (SMOS) Soil Moisture Over Watershed Networks in the U.S. Geoscience and Remote Sensing, IEEE Transactions on, 50, 1530-1543

Jackson, T.J., Cosh, M.H., Bindlish, R., Starks, P.J., Bosch, D.D., Seyfried, M., Goodrich, D.C., Moran, M.S. \& Jinyang, D. (2010). Validation of Advanced Microwave Scanning Radiometer Soil Moisture Products. Geoscience and Remote Sensing, IEEE Transactions on, 48, 4256-4272

Jacquette, E., Al Bitar, A., Mialon, A., Kerr, Y., Quesney, A., Cabot, F. \& Richaume, P. (2010). SMOS CATDS level 3 global products over land. Proc.SPIE, Remote Sensing for Agriculture, Ecosystems, and Hydrology XII, 78240K, 7824

Kerr, Y., Jacquette, E., Al Bitar, A., Cabot, F., Mialon, A., Richaume , P., Quesney, A., Berthon, L. \& Wigneron, J. (2013). CATDS SMOS L3 soil moisture retrieval processor, Algorithm Theoretical Baseline Document (ATBD). SO-TN-CBSA-GS-0029, 14/07/2013 
Kerr, Y.H. \& Njoku, E.G. (1990). A semiempirical model for interpreting microwave emission from semiarid land surfaces as seen from space. Geoscience and Remote Sensing, IEEE Transactions on, 28, 384-393

Kerr, Y.H., Vergely, J.L., Waldteufel, P., Richaume , P., Anterrieu, E. \& Moreno, R. (2008). CATDS SMOS L3 processor: Algorithm Theoretical Baseline Document for the soil moisture retrieval (ATBD). CNES-CESBIO, Toulouse, France, CATDS-ATBD-SM-L3, V1.1

Kerr, Y.H., Waldteufel, P., Richaume, P., Wigneron, J.P., Ferrazzoli, P., Mahmoodi, A., Al Bitar, A., Cabot, F., Gruhier, C., Juglea, S.E., Leroux, D., Mialon, A. \& Delwart, S. (2012). The SMOS Soil Moisture Retrieval Algorithm. Geoscience and Remote Sensing, IEEE Transactions on, 50, 1384-1403

Kerr, Y.H., Waldteufel, P., Wigneron, J.P., Delwart, S., Cabot, F., Boutin, J., Escorihuela, M.J., Font, J., Reul, N., Gruhier, C., Juglea, S.E., Drinkwater, M.R., Hahne, A., Martin-Neira, M. \& Mecklenburg, S. (2010). The SMOS Mission: New Tool for Monitoring Key Elements ofthe Global Water Cycle. Proceedings of the IEEE, 98, 666-687

Kerr, Y.H., Waldteufel, P., Wigneron, J.P., Martinuzzi, J., Font, J. \& Berger, M. (2001). Soil moisture retrieval from space: the Soil Moisture and Ocean Salinity (SMOS) mission. Geoscience and Remote Sensing, IEEE Transactions on, 39, 1729-1735

Koike, T., Nakamura, Y., Kaihotsu, I., Davva, G., Matsuura, N., Tamagawa, K. \& Fujii, H. (2004). Development of an advanced microwave scanning radiometer (AMSR-E) algorithm of soil moisture and vegetation water content. Annual Journal of Hydraulic Engineering, JSCE, 48

Koster, R.D., Dirmeyer, P.A., Guo, Z., Bonan, G., Chan, E., Cox, P., Gordon, C.T., Kanae, S., Kowalczyk, E., Lawrence, D., Liu, P., Lu, C.-H., Malyshev, S., McAvaney, B., Mitchell, K., Mocko, D., Oki, T., Oleson, K., Pitman, A., Sud, Y.C., Taylor, C.M., Verseghy, D., Vasic, R., Xue, Y. \& Yamada, T. (2004a). Regions of Strong Coupling Between Soil Moisture and Precipitation. Science, 305, 1138-1140

Koster, R.D., Guo, Z., Yang, R., Dirmeyer, P.A., Mitchell, K. \& Puma, M.J. (2009). On the Nature of Soil Moisture in Land Surface Models. Journal of Climate, 22, 4322-4335

Koster, R.D., Mahanama, S.P.P., Livneh, B., Lettenmaier, D.P. \& Reichle, R.H. (2010). Skill in streamflow forecasts derived from large-scale estimates of soil moisture and snow. Nature Geosci, 3, 613-616

Koster, R.D., Suarez, M.J., Liu, P., Jambor, U., Berg, A., Kistler, M., Reichle, R., Rodell, M. \& Famiglietti, J. (2004b). Realistic Initialization of Land Surface States: Impacts on Subseasonal Forecast Skill. Journal of Hydrometeorology, 5, 1049-1063

Koster, R.D., Sud, Y.C., Guo, Z., Dirmeyer, P.A., Bonan, G., Oleson, K.W., Chan, E., Verseghy, D., Cox, P., Davies, H., Kowalczyk, E., Gordon, C.T., Kanae, S., Lawrence, D., Liu, P., Mocko, D., Lu, C.-H., Mitchell, K., Malyshev, S., McAvaney, B., Oki, T., Yamada, T., Pitman, A., Taylor, C.M., Vasic, R. \& Xue, Y. (2006). GLACE: The Global LandAtmosphere Coupling Experiment. Part I: Overview. Journal of Hydrometeorology, 7, $590-610$

Lacava, T., Matgen, P., Brocca, L., Bittelli, M., Pergola, N., Moramarco, T. \& Tramutoli, V. (2012). A First Assessment of the SMOS Soil Moisture Product With In Situ and Modeled Data in Italy and Luxembourg. Geoscience and Remote Sensing, IEEE Transactions on, 50, 1612-1622 
Leroux, D.J., Kerr, Y.H., Richaume, P. \& Berthelot, B. (2011). Estimating SMOS error structure using triple collocation. In, Geoscience and Remote Sensing Symposium (IGARSS), 2011 IEEE International (pp. 24-27)

Li, L., Njoku, E.G., Im, E., Chang, P.S. \& Germain, K.S. (2004). A preliminary survey of radiofrequency interference over the U.S. in Aqua AMSR-E data. Geoscience and Remote Sensing, IEEE Transactions on, 42, 380-390

Mironov, V., Kerr, Y., Wigneron, J.P., Kosolapova, L. \& Demontoux, F. (2012). Temperatureand Texture-Dependent Dielectric Model for Moist Soils at 1.4 GHz. Geoscience and Remote Sensing Letters, IEEE, 10, 419-423

Mladenova, I., Lakshmi, V., Jackson, T.J., Walker, J.P., Merlin, O. \& de Jeu, R.A.M. (2011). Validation of AMSR-E soil moisture using L-band airborne radiometer data from National Airborne Field Experiment 2006. Remote Sensing of Environment, 115, 20962103

Muñoz-Sabater, J., Jarlan, L., Calvet, J.-C., Bouyssel, F. \& De Rosnay, P. (2007). From NearSurface to Root-Zone Soil Moisture Using Different Assimilation Techniques. Journal of Hydrometeorology, 8, 194-206

Njoku, E.G., Ashcroft, P., Chan, T.K. \& Li, L. (2005). Global Survey and Statistics of RadioFrequency Interference in AMSR-E Land Observations. IEEE Transactions on Geoscience and Remote Sensing,, 46

Njoku, E.G. \& Chan, S.K. (2006). Vegetation and surface roughness effects on AMSR-E land observations. Remote Sensing of Environment, 100, 190-199

Njoku, E.G., Jackson, T.J., Lakshmi, V., Chan, T.K. \& Nghiem, S.V. (2003). Soil moisture retrieval from AMSR-E. Geoscience and Remote Sensing, IEEE Transactions on, 41, 215-229

Njoku, E.G. \& Li, L. (1999). Retrieval of land surface parameters using passive microwave measurements at 6-18 GHz. Geoscience and Remote Sensing, IEEE Transactions on, 37, 79-93

Oliva, R., Daganzo, E., Kerr, Y.H., Mecklenburg, S., Nieto, S., Richaume, P. \& Gruhier, C. (2012). SMOS Radio Frequency Interference Scenario: Status and Actions Taken to Improve the RFI Environment in the 1400-1427-MHz Passive Band. Geoscience and Remote Sensing, IEEE Transactions on, 50, 1427-1439

Owe, M., de Jeu, R. \& Holmes, T. (2008). Multisensor historical climatology of satellite-derived global land surface moisture. Journal of Geophysical Research: Earth Surface, 113, F01002

Owe, M., de Jeu, R. \& Walker, J. (2001). A methodology for surface soil moisture and vegetation optical depth retrieval using the microwave polarization difference index. IEEE Transactions on Geoscience and Remote Sensing, 39, 1643-1654

Parinussa, R., Meesters, A., Liu, Y., Dorigo, W., Wagner, W. \& de Jeu, R. (2011a). An Analytical Solution to Estimate the Error Structure of a Global Soil Moisture Dataset. IEEE Geoscience and remote sensing letters, 8, 779-783

Parinussa, R.M., Meesters, A.G.C.A., Liu, Y.Y., Dorigo, W., Wagner, W. \& de Jeu, R.A.M. (2011b). Error Estimates for Near-Real-Time Satellite Soil Moisture as Derived From the Land Parameter Retrieval Model. Geoscience and Remote Sensing Letters, IEEE, 8, 779783 
Quesada, B., Vautard, R., Yiou, P., Hirschi, M. \& Seneviratne, S.I. (2012). Asymmetric European summer heat predictability from wet and dry southern winters and springs. Nature Clim. Change, 2, 736-741

Reichle, R.H., Crow, W.T. \& Keppenne, C.L. (2008). An adaptive ensemble Kalman filter for soil moisture data assimilation. Water Resources Research, 44, W03423

Reichle, R.H., Koster, R.D., Liu, P., Mahanama, S.P.P., Njoku, E.G. \& Owe, M. (2007). Comparison and assimilation of global soil moisture retrievals from the Advanced Microwave Scanning Radiometer for the Earth Observing System (AMSR-E) and the Scanning Multichannel Microwave Radiometer (SMMR). Journal of Geophysical Research: Atmospheres, 112, D09108

Rüdiger, C., Calvet, J.-C., Gruhier, C., Holmes, T.R.H., de Jeu, R.A.M. \& Wagner, W. (2009). An Intercomparison of ERS-Scat and AMSR-E Soil Moisture Observations with Model Simulations over France. Journal of Hydrometeorology, 10

Sahoo, A.K., Houser, P.R., Ferguson, C., Wood, E.F., Dirmeyer, P.A. \& Kafatos, M. (2008). Evaluation of AMSR-E soil moisture results using the in-situ data over the Little River Experimental Watershed, Georgia. Remote Sensing of Environment, 112, 3142-3152

Saleh, K., Kerr, Y.H., Richaume, P., Escorihuela, M.J., Panciera, R., Delwart, S., Boulet, G., Maisongrande, P., Walker, J.P., Wursteisen, P. \& Wigneron, J.P. (2009). Soil moisture retrievals at L-band using a two-step inversion approach (COSMOS/NAFE'05 Experiment). Remote Sensing of Environment, 113, 1304-1312

Sanchez, N., Martinez-Fernandez, J., Scaini, A. \& Perez-Gutierrez, C. (2012). Validation of the SMOS L2 Soil Moisture Data in the REMEDHUS Network (Spain). Geoscience and Remote Sensing, IEEE Transactions on, 50, 1602-1611

Scipal, K., Drusch, M. \& Wagner, W. (2008). Assimilation of a ERS scatterometer derived soil moisture index in the ECMWF numerical weather prediction system. Advances in Water Resources, 31, 1101-1112

Seneviratne, S., Wilhelm M, Stanelle T, van den Hurk B, Hagemann S, Berg A, Cheruy F, Higgins ME, Meier A, Brovkin V, Claussen M, Ducharne A, Dufresne JL, Findell K, Ghattas J, Lawrence DM, Malyshev S, Rumukainen M \& B, S. (2013). Impact of soil moisture-climate feedbacks on CMIP5 projections: First results from the GLACE-CMIP5 experiment. Geophys. Res. Lett.,, 40

Su, Z., Wen, J., Dente, L., van der Velde, R., Wang, L., Ma, Y., Yang, K. \& Hu, Z. (2011). The Tibetan Plateau observatory of plateau scale soil moisture and soil temperature (TibetObs) for quantifying uncertainties in coarse resolution satellite and model products Hydrol. Earth Syst. Sci., 15

Taylor, C.M., de Jeu, R.A.M., Guichard, F., Harris, P.P. \& Dorigo, W.A. (2012). Afternoon rain more likely over drier soils. Nature, 489, 423-426

Teuling, A.J., Seneviratne, S.I., Stockli, R., Reichstein, M., Moors, E., Ciais, P., Luyssaert, S., van den Hurk, B., Ammann, C., Bernhofer, C., Dellwik, E., Gianelle, D., Gielen, B., Grunwald, T., Klumpp, K., Montagnani, L., Moureaux, C., Sottocornola, M. \& Wohlfahrt, G. (2010). Contrasting response of European forest and grassland energy exchange to heatwaves. Nature Geosci, 3, 722-727

Thirel, G., Martin, E., Mahfouf, J.F., Massart, S., Ricci, S., Regimbeau, F. \& Habets, F. (2010). A past discharge assimilation system for ensemble streamflow forecasts over France Part 2: Impact on the ensemble streamflow forecasts. Hydrol. Earth Syst. Sci., 14, 16391653 
van den Hurk, B. \& Viterbo, P. (2003). The Torne-Kalix PILPS 2(e) experiment as a test bed for modifications to the ECMWF land surface scheme. Global and Planetary Change, 38, $165-173$

Vivoni, E.R., Gebremichael, M., Watts, C.J., Bindlish, R. \& Jackson, T.J. (2008). Comparison of ground-based and remotely-sensed surface soil moisture estimates over complex terrain during SMEX04. Remote Sensing of Environment, 112, 314-325

Wagner, W., Bloeschl, G., Pampaloni, P., Calvet, J.-C., Bizzarri, B., Wigneron, J.-P. \& Kerr, Y. (2007). Operational readiness of microwave remote sensing of soil moisture for hydrologic applications. Nordic Hydrology, 38, 1-20

Walker, J.P., Willgoose, G.R. \& Kalma, J.D. (2004). In situ measurement of soil moisture: a comparison of techniques. Journal of Hydrology, 293, 85-99

Wang, J.R. (1985). Effect of vegetation on soil moisture sensing observed from orbiting microwave radiometers. Remote Sensing of Environment, 17, 141-151

Wigneron, J.-P., Schwank, M., Baeza, E.L., Kerr, Y., Novello, N., Millan, C., Moisy, C., Richaume, P., Mialon, A., Al Bitar, A., Cabot, F., Lawrence, H., Guyon, D., Calvet, J.-C., Grant, J.P., Casal, T., de Rosnay, P., Saleh, K., Mahmoodi, A., Delwart, S. \& Mecklenburg, S. (2012). First evaluation of the simultaneous SMOS and ELBARA-II observations in the Mediterranean region. Remote Sensing of Environment, 124, 26-37

Wigneron, J.P., Calvet, J.C., Kerr, Y., Chanzy, A. \& Lopes, A. (1993). Microwave emission of vegetation: sensitivity to leaf characteristics. Geoscience and Remote Sensing, IEEE Transactions on, 31, 716-726

Wigneron, J.P., Calvet, J.C., Pellarin, T., Van de Griend, A.A., Berger, M. \& Ferrazzoli, P. (2003). Retrieving near-surface soil moisture from microwave radiometric observations: current status and future plans. Remote Sensing of Environment, 85, 489-506

Wigneron, J.P., Kerr, Y., Waldteufel, P., Saleh, K., Escorihuela, M.J., Richaume, P., Ferrazzoli, P., de Rosnay, P., Gurney, R., Calvet, J.C., Grant, J.P., Guglielmetti, M., Hornbuckle, B., Mätzler, C., Pellarin, T. \& Schwank, M. (2007). L-band Microwave Emission of the Biosphere (L-MEB) Model: Description and calibration against experimental data sets over crop fields. Remote Sensing of Environment, 107, 639-655

Wigneron, J.P., Waldteufel, P., Chanzy, A., Calvet, J.C. \& Kerr, Y. (2000). Two-Dimensional Microwave Interferometer Retrieval Capabilities over Land Surfaces (SMOS Mission). Remote Sensing of Environment, 73, 270-282 
1006

1007

1008 
1009

1010 Table 1 Main characteristics of the surface soil moisture datasets used in this study. Note that all products 1011 are daily and global products re-sampled to $0.25^{\circ}(\sim 25 \mathrm{~km})$.

\begin{tabular}{|c|c|c|c|c|c|}
\hline Soil moisture datasets & Incidence angle $\left(^{\circ}\right)$ & Data type and frequency & Sampling depth and unit & Temporal coverage & Reference \\
\hline $\begin{array}{l}\text { SMOS level } 3 \\
\text { (SMOSL3) }\end{array}$ & $0-55$ & $\begin{array}{l}\text { Remotely sensed } \\
\text { (L-band, passive) }\end{array}$ & $\sim 0-3 \mathrm{~cm}\left(\mathrm{~m}^{3} / \mathrm{m}^{3}\right)$ & 2010 - Present & Jacquette et al. (2010) \\
\hline $\begin{array}{l}\text { AMSR-E , NASA- } \\
\text { VUA Algorithm } \\
\text { (AMSRM) }\end{array}$ & 55 & $\begin{array}{l}\text { Remotely sensed } \\
\text { (C-band, passive) }\end{array}$ & $\sim 0-1 \mathrm{~cm}\left(\mathrm{~m}^{3} / \mathrm{m}^{3}\right)$ & $2002-2011$ & Owe et al. (2008) \\
\hline $\begin{array}{l}\text { ECMWF } \\
\text { SM-DAS-2 } \\
\text { (DAS2) }\end{array}$ & - & $\begin{array}{l}\text { Land Data Assimilation } \\
\text { System }\end{array}$ & $0-7 \mathrm{~cm}\left(\mathrm{~m}^{3} / \mathrm{m}^{3}\right)$ & 2010 - Present & $\begin{array}{l}\text { de Rosnay et al. (2013) } \\
\text { Drusch et al. (2009) }\end{array}$ \\
\hline
\end{tabular}

1012

1013

1014

1015

1016

1017

1018

1019

1020

1021

1022

1023

1024

1025

1026

1027 
Table 2 Locations and type of biome of the eight sites selected to evaluate the SSM time series (Fig. 2). All sites have the same surface area (i.e., $\sim 360000 \mathrm{~km}^{2}$ ).

\begin{tabular}{|c|c|c|c|c|}
\hline & Region & $\begin{array}{l}\text { Coordinates (centre) } \\
\text { (longitude - latitude) }\end{array}$ & Biome (vegetation) & $\begin{array}{l}\text { Köppen-Geiger Climate } \\
\text { classification }\end{array}$ \\
\hline 1 & Brazil, Amazon Basin & $\left(-53^{\circ} \mathrm{W}--8^{\circ} \mathrm{S}\right)$ & $\begin{array}{l}\text { Tropical humid } \\
\text { (evergreen rain forest) }\end{array}$ & Af \& Am \\
\hline 2 & Deccan Plateau Region of India & $\left(78^{\circ} \mathrm{E}-21^{\circ} \mathrm{N}\right)$ & $\begin{array}{l}\text { Tropical semi-arid } \\
\text { (Isolated trees and bush } \\
\text { in open grassland) }\end{array}$ & BSk, Aw, \& BSh \\
\hline 3 & Central Australia & $\left(133{ }^{\circ} \mathrm{E}--23{ }^{\circ} \mathrm{S}\right)$ & Desert temperate & $\mathrm{BWh}$ \\
\hline 4 & $\begin{array}{l}\text { North-West America, Great Basin } \\
\text { Region (Nevada, Utah, Idaho and } \\
\text { Washington) }\end{array}$ & $\left(-114^{\circ} \mathrm{W}-40^{\circ} \mathrm{N}\right)$ & Desert temperate & BWh \& BWk \\
\hline 5 & $\begin{array}{l}\text { North-East America, Interior Plains } \\
\text { Region (Iowa, Illinois, Minnesota, } \\
\text { and Wisconsin) }\end{array}$ & $\left(-94^{\circ} \mathrm{W}-43^{\circ} \mathrm{N}\right)$ & $\begin{array}{l}\text { Temperate humid (forest, } \\
\text { grass land, agriculture) }\end{array}$ & Aw \& Dfa \\
\hline 6 & $\begin{array}{l}\text { Sahel, Savanna Region of Nigeria, } \\
\text { Cameroon, Central African Republic } \\
\text { and Chad }\end{array}$ & $\left(18^{\circ} \mathrm{E}-89^{\circ} \mathrm{N}\right)$ & $\begin{array}{l}\text { Tropical semi-arid } \\
\text { (Isolated trees and bush } \\
\text { in open grassland) }\end{array}$ & Aw \\
\hline 7 & $\begin{array}{l}\text { Central Europe (Austria, France, } \\
\text { Germany and Italy) }\end{array}$ & $\left(4^{\circ} \mathrm{E}-47^{\circ} \mathrm{N}\right)$ & $\begin{array}{l}\text { Temperate forest } \\
\text { (Deciduous broadleaf } \\
\text { forest) }\end{array}$ & $\mathrm{Cfb}$ \\
\hline 8 & Argentina, Pampas Region & $\left(-53^{\circ} \mathrm{W}--26^{\circ} \mathrm{S}\right)$ & $\begin{array}{l}\text { Temperate humid (grass } \\
\text { land) }\end{array}$ & $\mathrm{Cfa}$ \\
\hline
\end{tabular}


Figure captions

Fig. 1. Probability of Radio Frequency Interference (RFI) occurrences in the L-band SMOS observations. The map represents the average probability of RFI occurrences for the period $2010-2012$.

Fig. 2. Distribution of major biomes (Chesworth, 2008). The boxes on the map indicate the sites which were selected to illustrate the main features of the SMOSL3, AMSRM and DAS2 products for a variety of vegetation and climatic conditions.

Fig. 3. Global map of the long term mean LAI in $\mathrm{m}^{2} \cdot \mathrm{m}^{-2}$ (Dirmeyer et al., 2006).

Fig. 4. Spatio-temporal comparison between SMOSL3 ascending (ASC) and SMOSL3 descending (DESC) products in terms of correlation with respect to the reference (DAS2) product for the period 03/2010 - 09/2011. The map shows the areas where either SMOSL3 ASC (red) or SMOSL3 DESC (green) correlates better with the reference. Pixels where ASC and DESC have similar performances (differences in the values of $\mathrm{R}$ are lower than 0.05 ) are shown in blue. Only significant correlations (pvalue $<0.05)$ are presented.

Fig. 5. Comparison of the time series of the mean SSM (site averaged) derived from SMOSL3, AMSRM and DAS2 for the period 03/2010 - 09/2011 for the eight selected sites shown in Fig. 2.

Fig. 6. Pairwise comparison between the AMSRM (left panel) and SMOSL3 (right panel) SSM products with respect to the reference DAS2 product in terms of the correlation coefficient $(\mathrm{R})$ based on original SSM data (a and b), the correlation coefficient (R) based on SSM anomalies (c and d), RMSD $\left(\mathrm{m}^{3} / \mathrm{m}^{3}\right.$; e and $\mathrm{f}$ ), and Bias $\left(\mathrm{m}^{3} / \mathrm{m}^{3} ; \mathrm{g}\right.$ and $\mathrm{h}$ ) for the period 03/2010 - 09/2011. Only significant correlations (p-value $<0.05)$ are presented.

Fig. 7. Pairwise comparison between the SMOSL3 and AMSRM SSM products with respect to the reference DAS2 SSM product in terms of correlations based on the original SSM data (a) or on SSM anomalies (b) for the period 03/2010 - 09/2011. The map show the areas where either SMOSL3 (red) or AMSRM (green) correlates better with the reference. Pixels where SMOSL3 and AMSRM have similar 
performances (differences in the values of $\mathrm{R}$ are lower than 0.05) are shown in blue. Only significant correlations (p-value $<0.05)$ are presented.

Fig. 8. Distribution of the statistical indicators between SMOSL3 (red) and AMSRM (green) and the reference as a function of biome types for the period 03/2010 - 09/2011. Statistics in terms of correlation coefficient based on original SSM data (a), correlation coefficient based on SSM anomalies (b), RMSD $\left(\mathrm{m}^{3} / \mathrm{m}^{3} ; \mathrm{c}\right)$, and Bias $\left(\mathrm{m}^{3} / \mathrm{m}^{3} ; \mathrm{d}\right)$ are computed at each grid cell and then averaged by biome type. The biome types are defined from the classification given by Chesworth (2008) shown in Fig. 2. Error bars represent mean \pm Standard Deviation $(\mathrm{SD})$ and only significant correlations (p-value $<0.05)$ are considered in the analysis.

Fig. 9. Distribution of the correlation coefficient (R) between SMOSL3 (red), AMSRM (green) and the reference dataset (DAS2) for the original SSM data (a) and anomalies (b) as a function of LAI for the period 03/2010 - 09/2011. Statistics are computed at each grid cell and then averaged by LAI intervals. The values of LAI were extracted from the map of Dirmeyer et al. (2006) shown in Fig. 3. The percentage value (top of figure) provides the cover fraction (\%) over continental surfaces corresponding to each LAI interval. Error bars represent mean \pm Standard Deviation (SD) and only significant correlations (p-value $<$ $0.05)$ are considered in the analysis. 

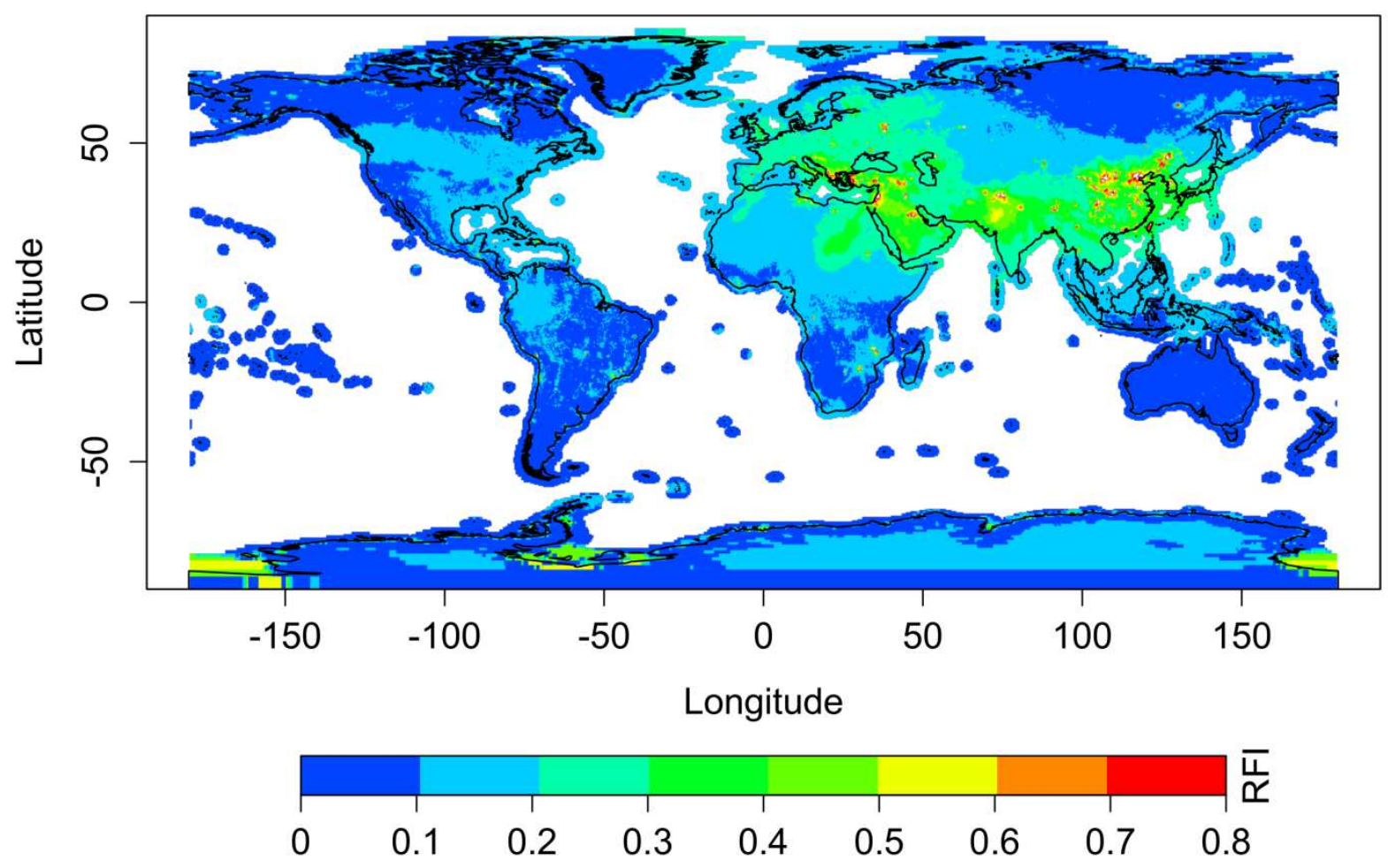

1089

1090

1091

1092

1093

1094

1095

1096

1097

1098

1099

1100

1101

1102

1103

1104

1105

1106
Fig. 1. Probability of Radio Frequency Interference (RFI) occurrences in the L-band SMOS observations. The map represents the average probability of RFI occurrences for the period $2010-2012$. 
1107

1108

1109

1110

1111

1112

1113

1114

1115

1116

1117

1118

1119

1120

1121

1122

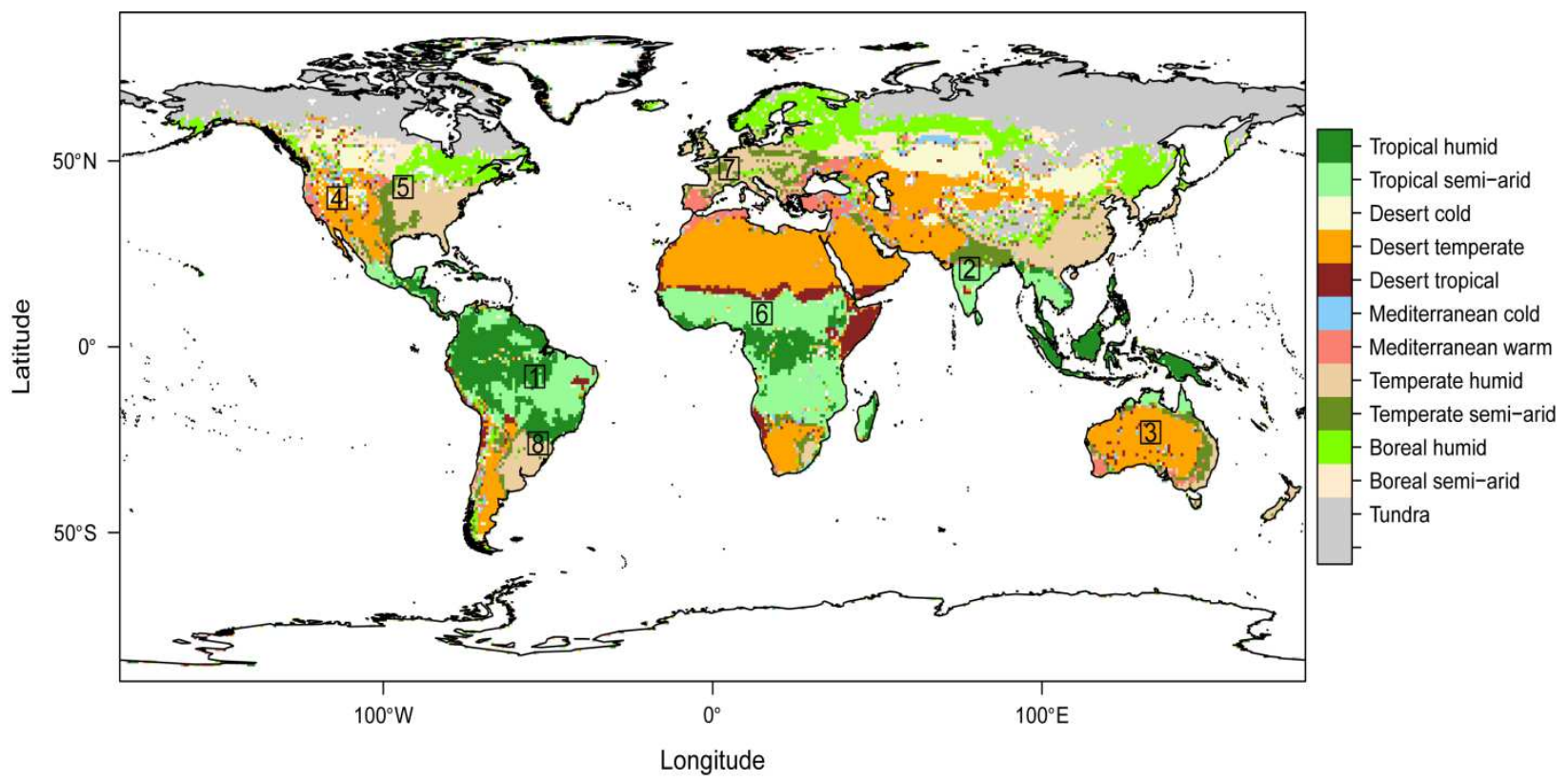

Fig. 2. Distribution of major biomes (Chesworth, 2008). The boxes on the map indicate the sites which were selected to illustrate the main features of the SMOSL3, AMSRM and DAS2 products for a variety of vegetation and climatic conditions. 


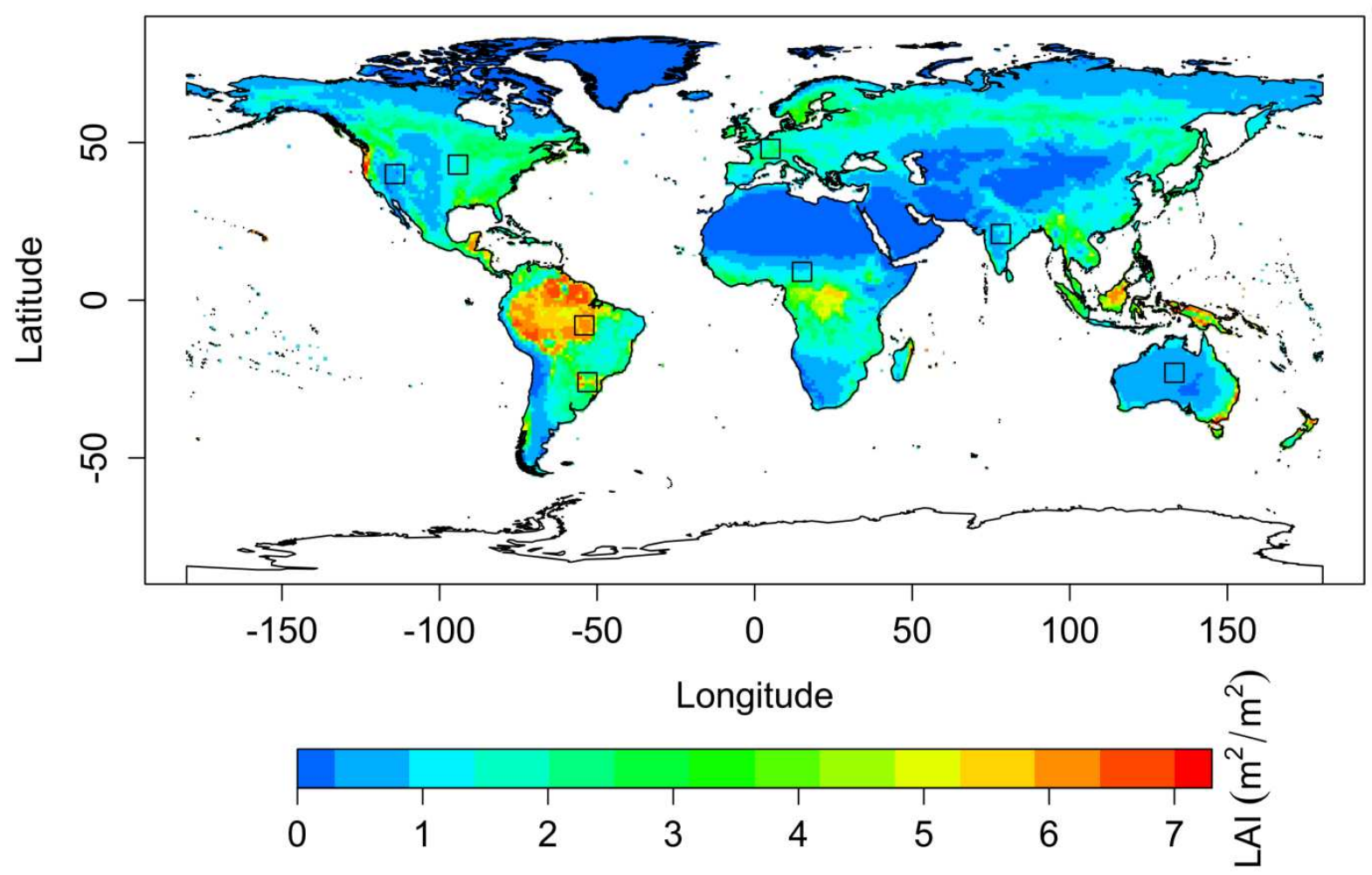

1126

1127 Fig. 3. Global map of the long term mean LAI in $\mathrm{m}^{2} \cdot \mathrm{m}^{-2}$ (Dirmeyer et al., 2006).

1128

1129

1130

1131

1132

1133

1134

1135

1136

1137 


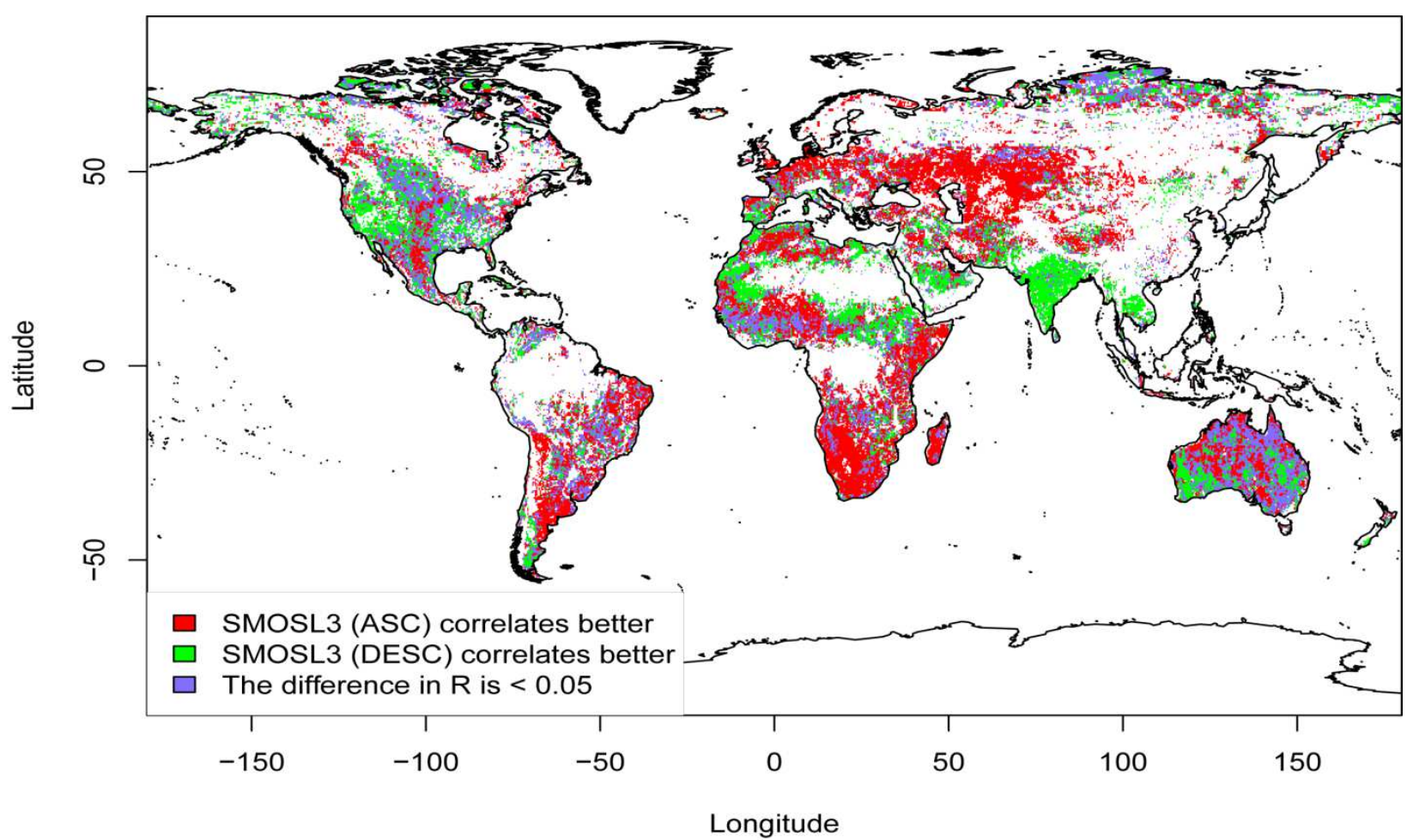

Fig. 4. Spatio-temporal comparison between SMOSL3 ascending (ASC) and SMOSL3 descending (DESC) products in terms of correlation with respect to the reference (DAS2) product for the period 03/2010-09/2011. The map shows the areas where either SMOSL3 ASC (red) or SMOSL3 DESC (green) correlates better with the reference. Pixels where ASC and DESC have similar performances (differences in the values of $\mathrm{R}$ are lower than 0.05) are shown in blue. Only significant correlations ( $\mathrm{p}$-value $<$ $0.05)$ are presented. 

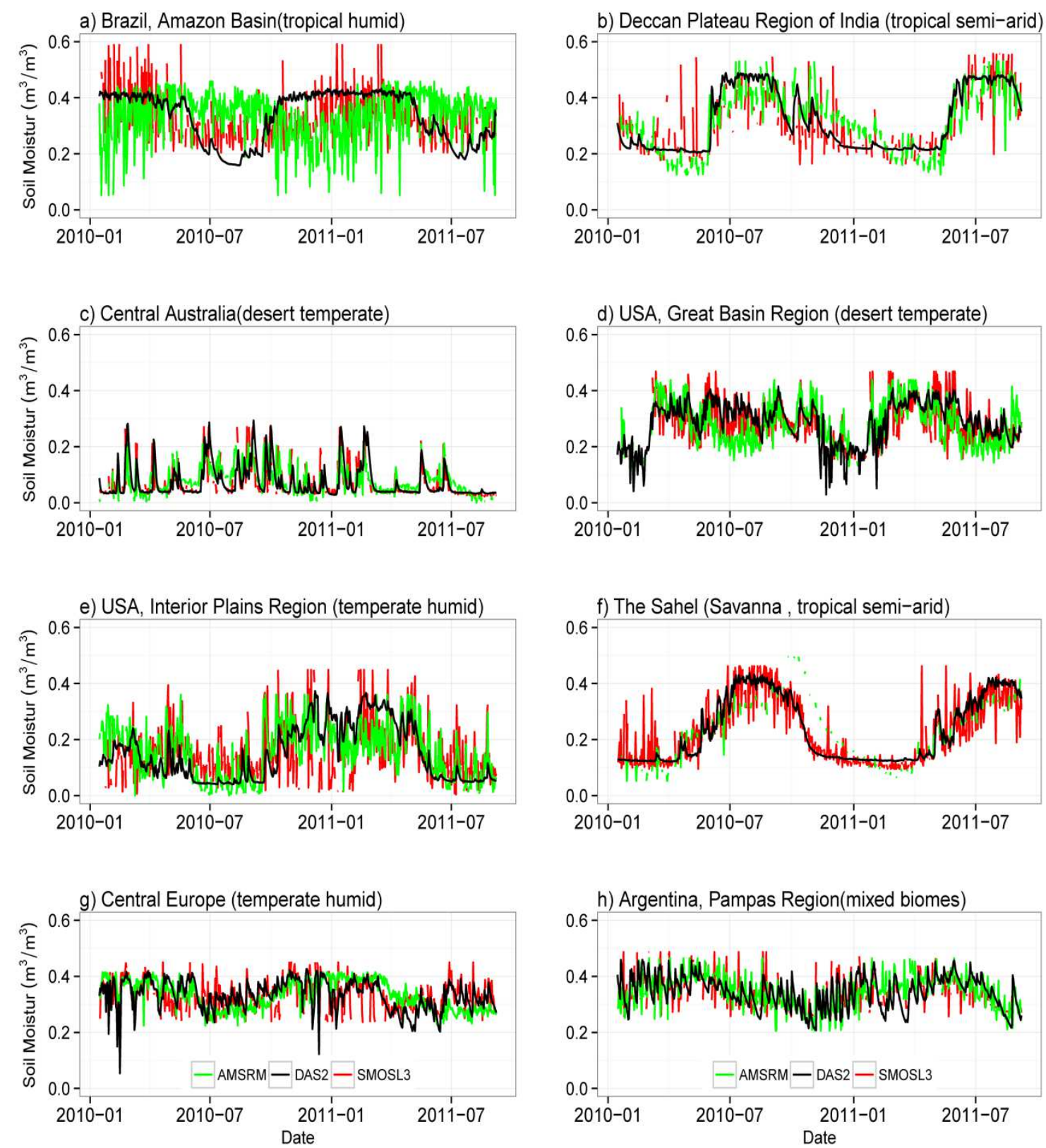

1155

Fig. 5. Comparison of the time series of the mean SSM (site averaged) derived from SMOSL3, AMSRM and DAS2 for the period 03/2010 - 09/2011 for the eight selected sites shown in Fig. 2. 

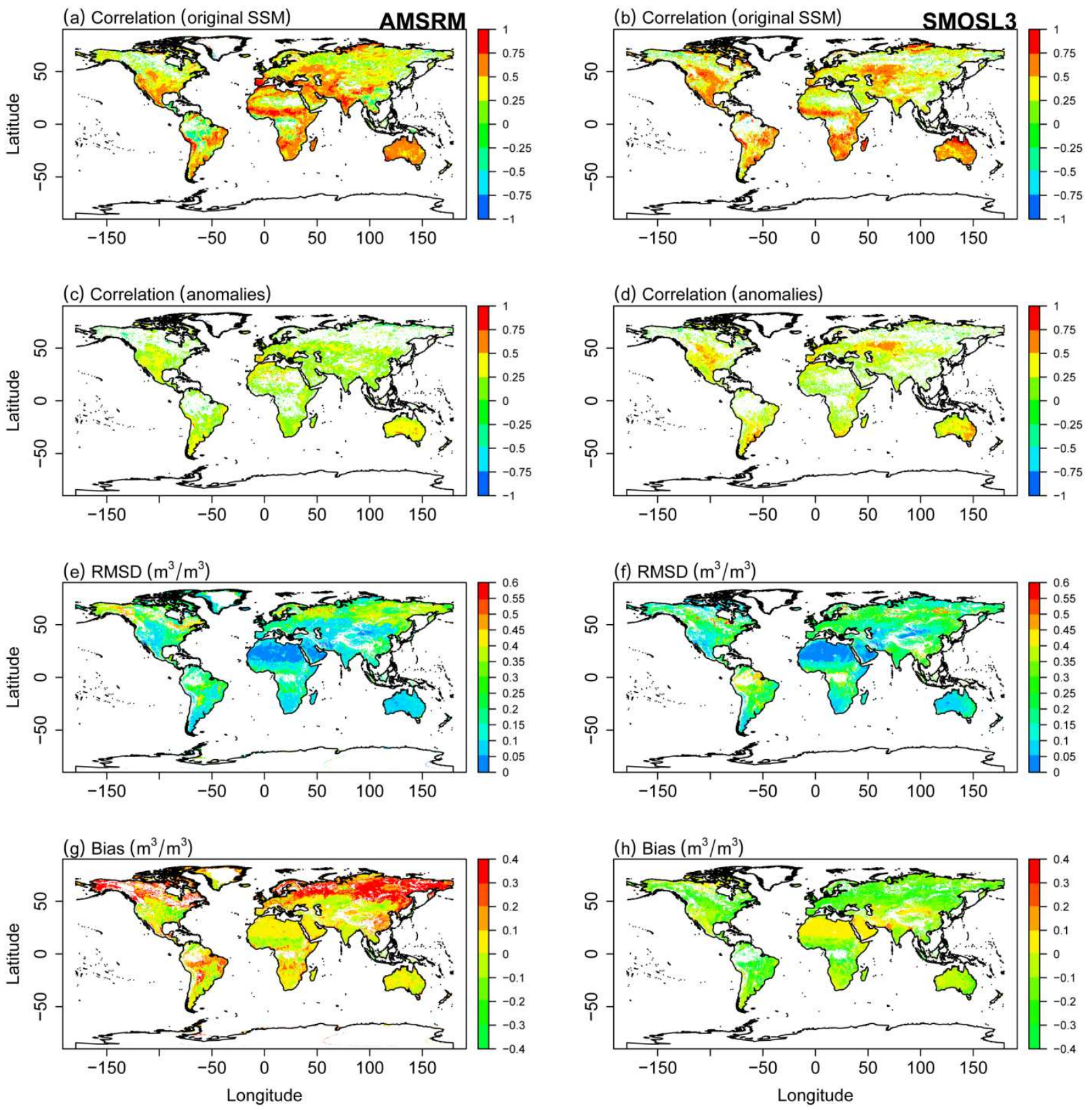

164 1165

1166

1167

1168

1169

1170

1171

1172

Fig. 6. Pairwise comparison between the AMSRM (left panel) and SMOSL3 (right panel) SSM products with respect to the reference DAS2 product in terms of the correlation coefficient $(\mathrm{R})$ based on original SSM data (a and b), the correlation coefficient (R) based on SSM anomalies (c and d), RMSD $\left(\mathrm{m}^{3} / \mathrm{m}^{3}\right.$; e and $\left.\mathrm{f}\right)$, and Bias $\left(\mathrm{m}^{3} / \mathrm{m}^{3}\right.$; g and h) for the period $03 / 2010-$ 09/2011. Only significant correlations (p-value $<0.05$ ) are presented. 
(a) Correlation (original SSM)

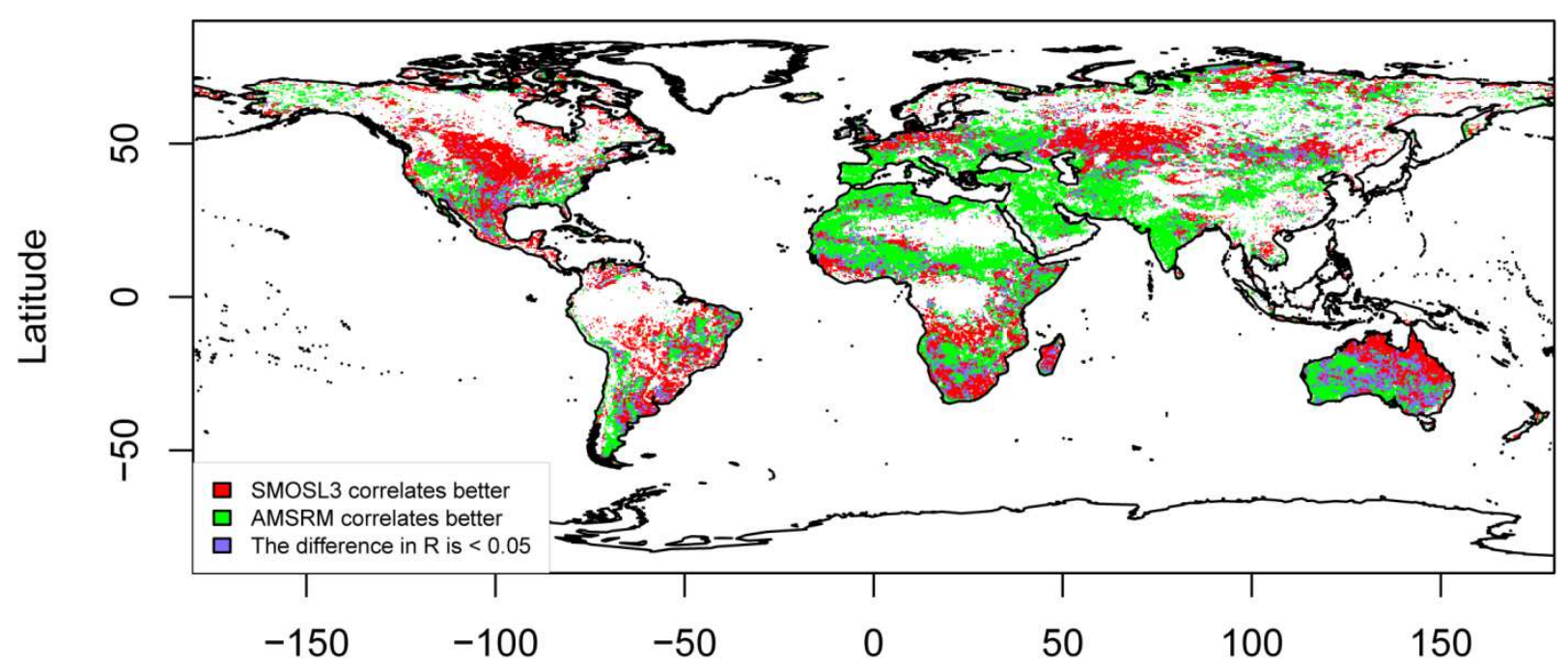

(b) Correlation (anomalies)

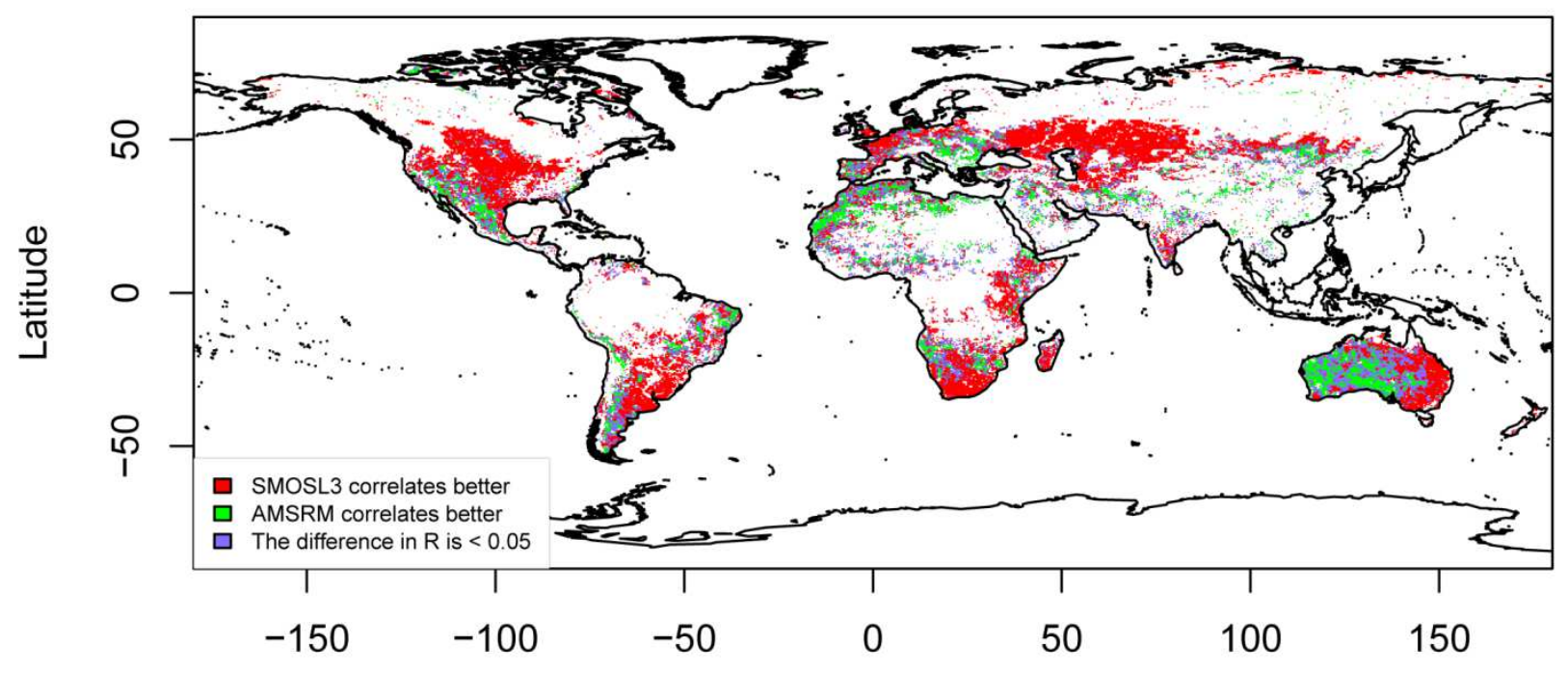

\section{Longitude}

Fig. 7. Pairwise comparison between the SMOSL3 and AMSRM SSM products with respect to the reference DAS2 SSM product in terms of correlations based on the original SSM data (a) or on SSM anomalies (b) for the period 03/2010 - 09/2011. The map show the areas where either SMOSL3 (red) or AMSRM (green) correlates better with the reference. Pixels where SMOSL3 and AMSRM have similar performances (differences in the values of R are lower than 0.05 ) are shown in blue. Only significant correlations (p-value $<0.05)$ are presented. 
(a) Correlation (original SSM)

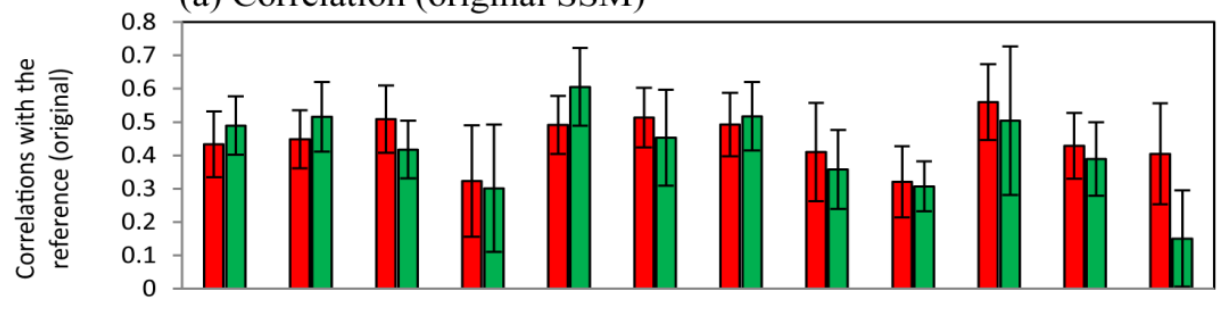

(b) Correlation (anomalies)

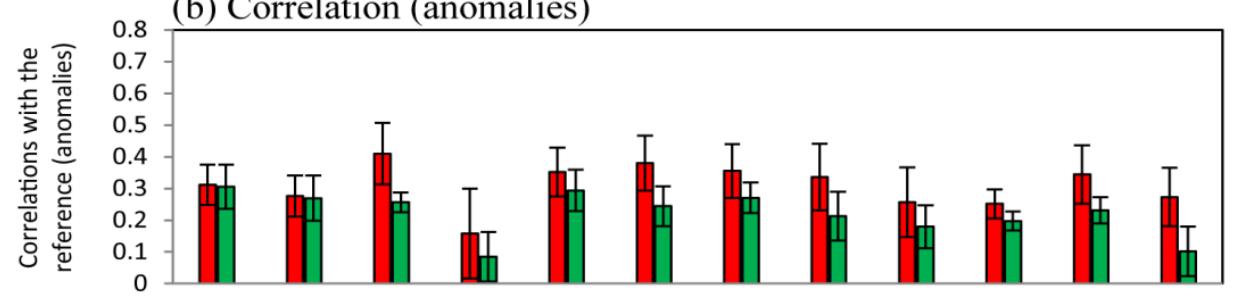

(c) $\operatorname{RMSD}\left(\mathrm{m}^{3} / \mathrm{m}^{3}\right)$

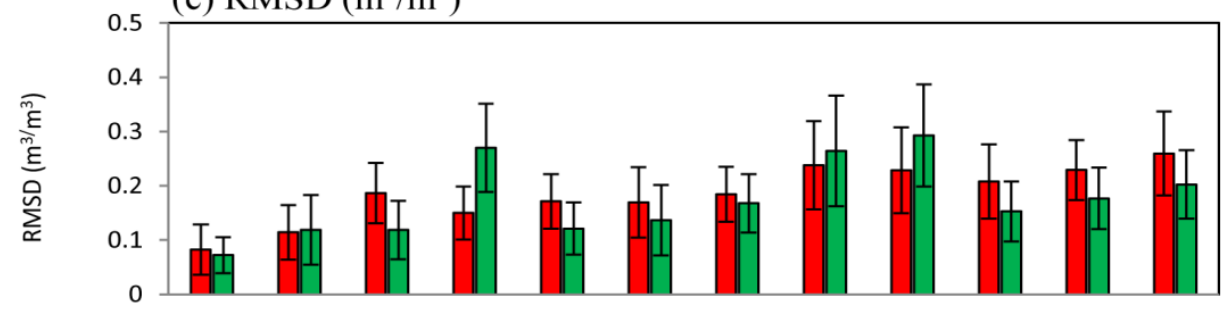

(d) $\operatorname{Bias}\left(\mathrm{m}^{3} / \mathrm{m}^{3}\right)$

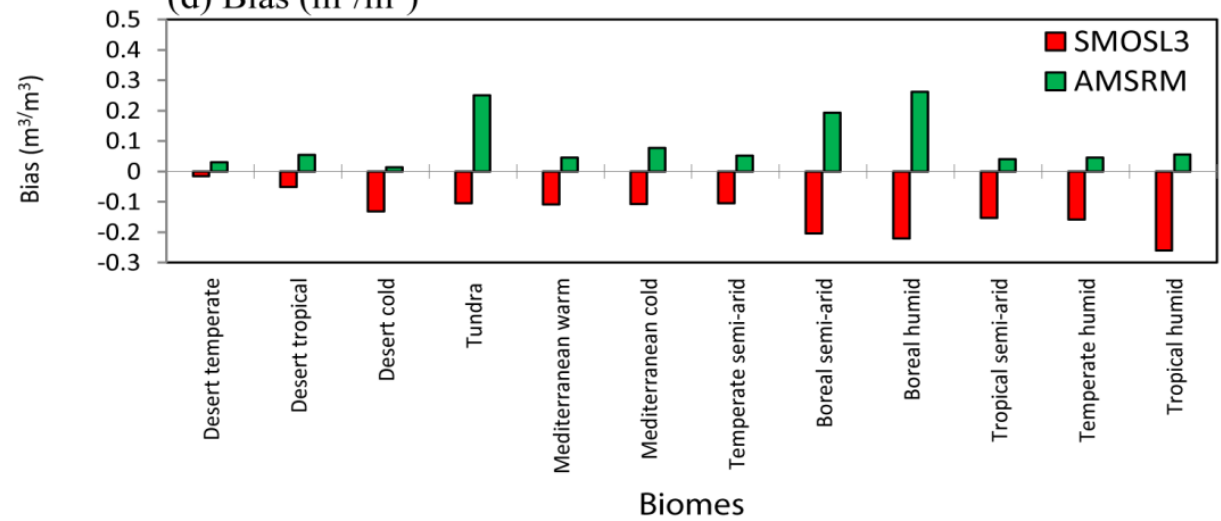

Fig. 8. Distribution of the statistical indicators between SMOSL3 (red) and AMSRM (green) and the reference as a function of biome types for the period 03/2010 - 09/2011. Statistics in terms of correlation coefficient based on original SSM data (a), correlation coefficient based on SSM anomalies (b), RMSD $\left(\mathrm{m}^{3} / \mathrm{m}^{3} ; \mathrm{c}\right)$, and Bias $\left(\mathrm{m}^{3} / \mathrm{m}^{3} ; \mathrm{d}\right)$ are computed at each grid cell and then averaged by biome type. The biome types are defined from the classification given by Chesworth (2008) shown in Fig. 2.

1187 Error bars represent mean \pm Standard Deviation $(\mathrm{SD})$ and only significant correlations $(\mathrm{p}$-value $<0.05)$ are considered in the 1188 analysis. 
(a) Correlation (original SSM)

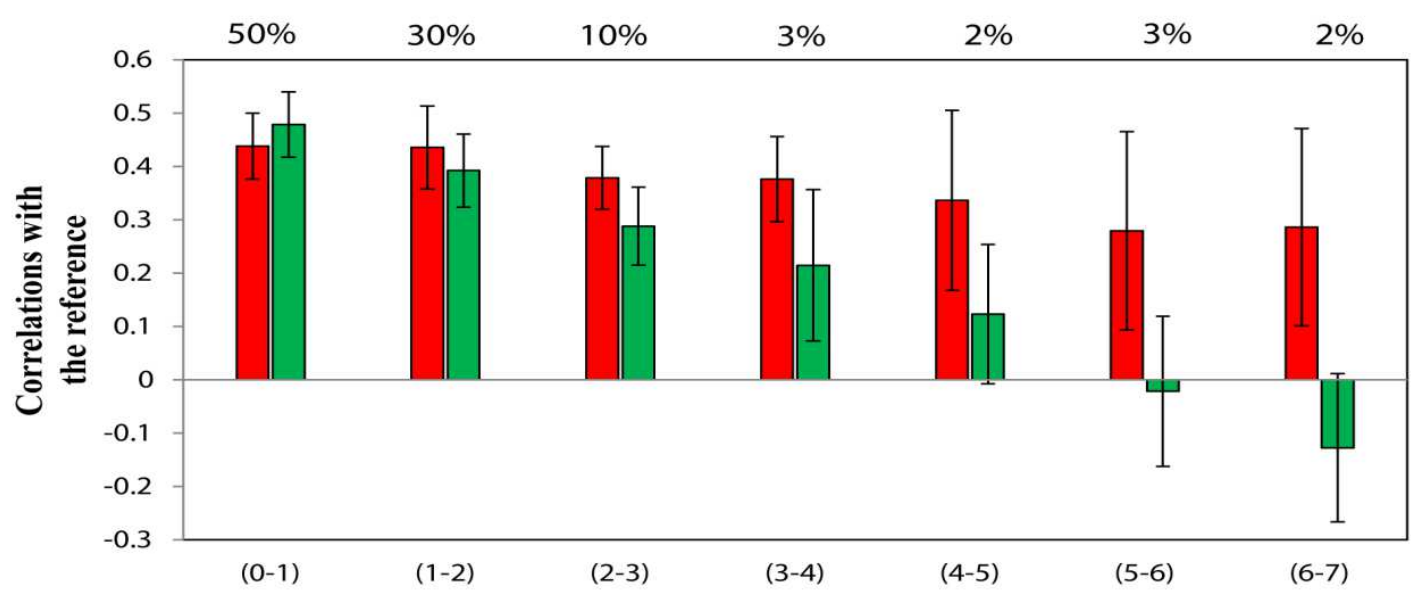

(b) Correlation (anomalies)

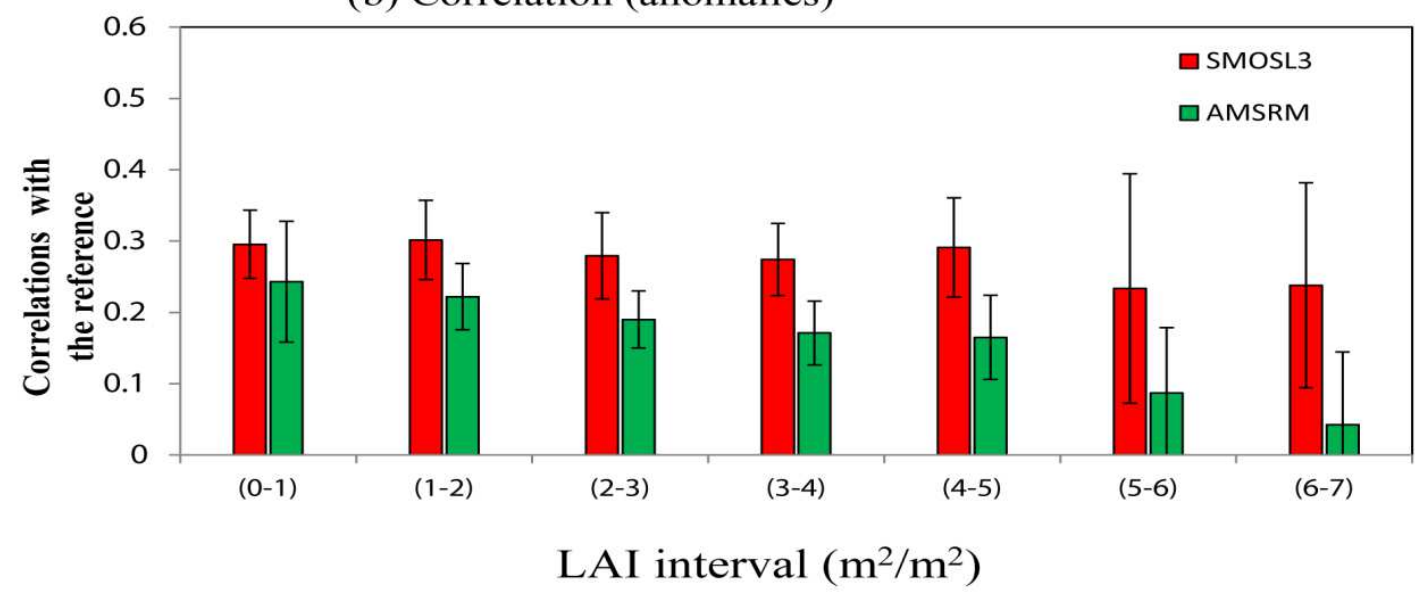

Fig. 9. Distribution of the correlation coefficient (R) between SMOSL3 (red), AMSRM (green) and the reference dataset (DAS2) for the original SSM data (a) and anomalies (b) as a function of LAI for the period 03/2010 - 09/2011. Statistics are computed at each grid cell and then averaged by LAI intervals. The values of LAI were extracted from the map of Dirmeyer et al. (2006) shown in Fig. 3. The percentage value (top of figure) provides the cover fraction (\%) over continental surfaces corresponding to each LAI interval. Error bars represent mean \pm Standard Deviation (SD) and only significant correlations (p-value $<0.05)$ are considered in the analysis. 